Florida International University FIU Digital Commons

\title{
DNA Aptamer Confirmation and Utilization for the Cyanotoxin, Cylindrospermopsin
}

Diane M. Catlin

Florida International University, dcat1003@fiu.edu

DOI: $10.25148 /$ etd.FIDC000770

Follow this and additional works at: https://digitalcommons.fiu.edu/etd

Part of the Analytical Chemistry Commons, Biochemistry Commons, and the Environmental Sciences Commons

\section{Recommended Citation}

Catlin, Diane M., "DNA Aptamer Confirmation and Utilization for the Cyanotoxin, Cylindrospermopsin" (2016). FIU Electronic Theses and Dissertations. 2552.

https://digitalcommons.fiu.edu/etd/2552 


\section{FLORIDA INTERNATIONAL UNIVERSITY}

Miami, Florida

\section{DNA APTAMER CONFIRMATION AND UTILIZATION FOR THE CYANOTOXIN, CYLINDROSPERMOPSIN}

A thesis submitted in partial fulfillment of the

requirements for the degree of

MASTER OF SCIENCE

in

FORENSIC SCIENCE

by

Diane M. Catlin

2016 
To: Dean Michael R. Heithaus

College of Arts, Sciences and Education

This thesis, written by Diane M. Catlin, and entitled DNA Aptamer Confirmation and Utilization for the Cyanotoxin, Cylindrospermopsin, having been approved in respect to style and intellectual content, is referred to you for judgment.

We have read this thesis and recommend that it be approved.

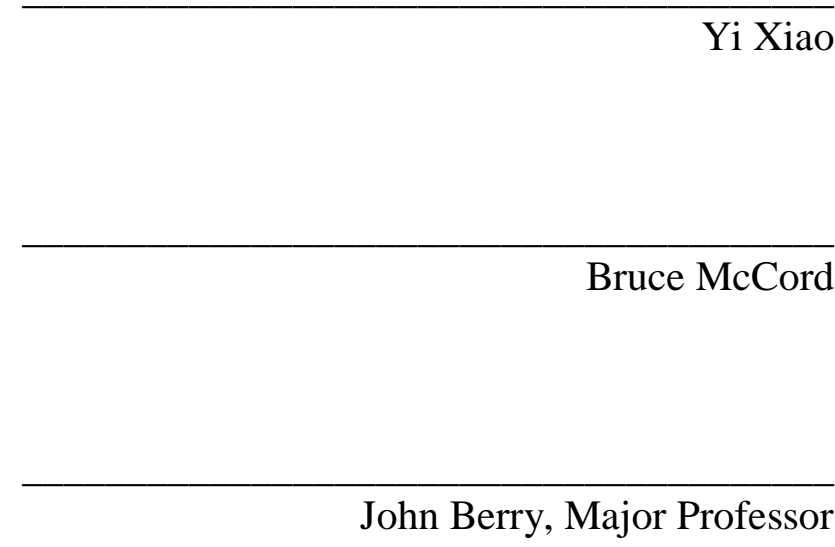

Date of Defense: July 8, 2016

The thesis of Diane M. Catlin is approved.

Dean Michael R. Heithaus

College of Arts, Sciences and Education

Andrés G. Gil

Vice President for Research and Economic Development and Dean of the University Graduate School

Florida International University, 2016 


\section{DEDICATION}

I dedicate this work to my mother, Denise Catlin. I would not have been able to complete this work without your support and guidance. I am truly grateful to have you. 


\section{ACKNOWLEDGMENTS}

I would like to thank my major professor, Dr. John Berry, for his guidance over the last several years of my graduate education. I want to thank my thesis committee for all the support they have given me and for taking the time to work with me.

I would also like to give special thanks to Dr. Yi Xiao and Juan Canoura. I would not be able to complete my thesis without the help and guidance Dr. Xiao gave me. My work would not have been complete with the many discussions and helpful instruction of her student, Juan Canoura.

Finally, I would like to thank all of my friends and family for the support they have given me. Your unconditional support and words of encouragement kept me going and helped me strive to be better. 
ABSTRACT OF THE THESIS

DNA APTAMER CONFIRMATION AND UTILIZATION FOR THE CYANOTOXIN, CYLINDROSPERMOPSIN

by

Diane M. Catlin

Florida International University, 2016

Miami, Florida

Professor John Berry, Major Professor

Cyanotoxins are posing an increasing threat to the health of humans and wildlife. Cylindrospermopsin is a cyanotoxin that occurs in warm climates and is harmful when ingested. The toxic effects of CYN can affect multiple organ systems. The effects, coupled with the evidence of a mass contamination of a water supply in Australia, prove that CYN needs to be investigated further.

Aptamers have become a desirable method for detection of CYN as a result of an aptamer's high specificity and the ability to scale up experiments. Aptamers have been designed to bind with a variety of targets, including cyanotoxins. An aptamer for CYN was identified by Elshafey et al.

This study aims to confirm the binding of the aptamer to CYN and the selectivity of the aptamer using fluorescent biosensing and circular dichroism. Aptamer affinity capture was used to investigate the possibility of a real world application of the aptamer. 


\section{TABLE OF CONTENTS}

CHAPTER

PAGE

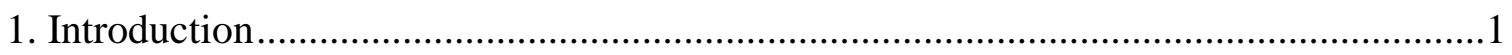

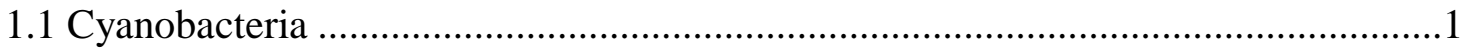

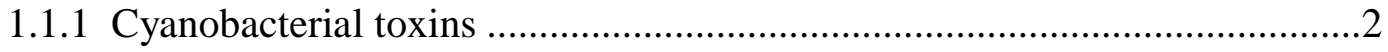

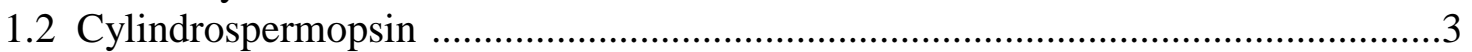

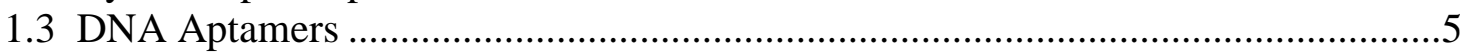

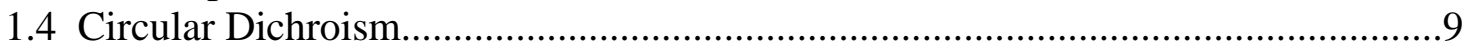

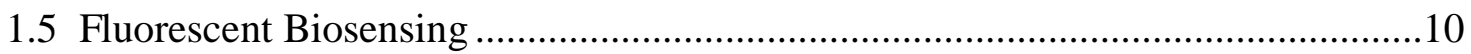

1.6 Aptamer Affinity Chromatography .................................................................10

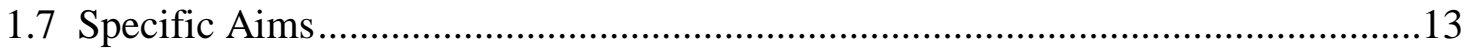

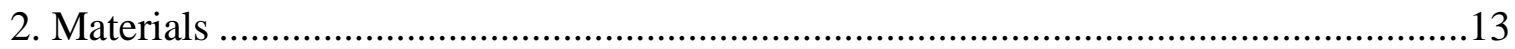

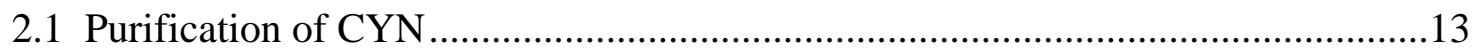

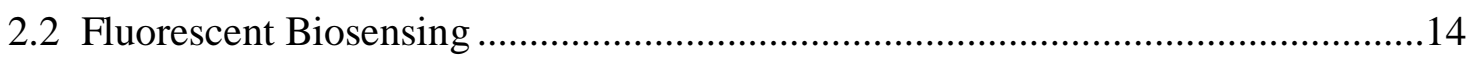

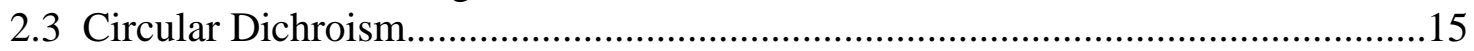

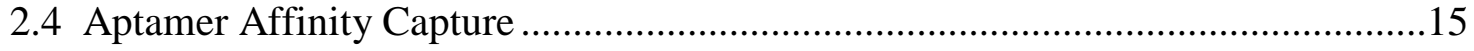

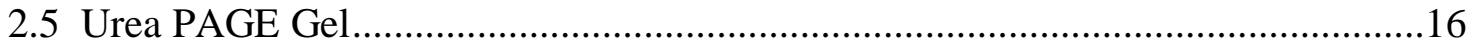

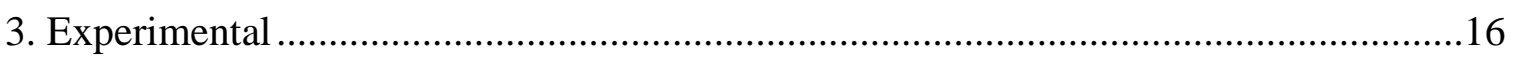

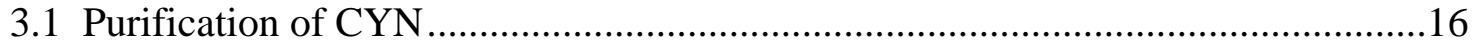

3.1.1 Pretreatment of Culture Medium and Biomass............................................17

3.1.2 Extraction of CYN from Culture Biomass....................................................17

3.1.3 Extraction of CYN from Culture Medium.................................................18

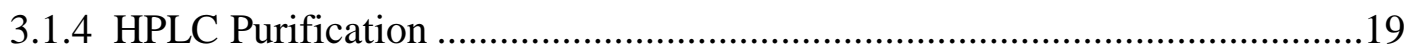

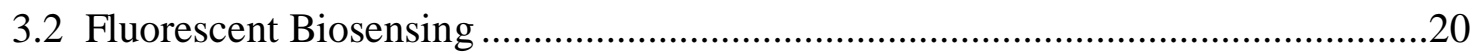

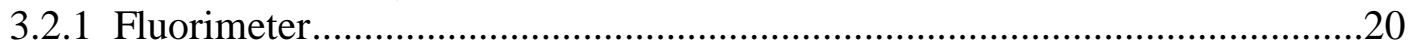

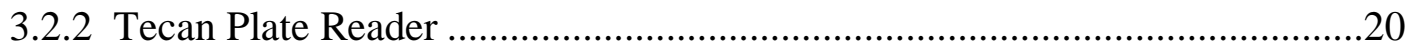

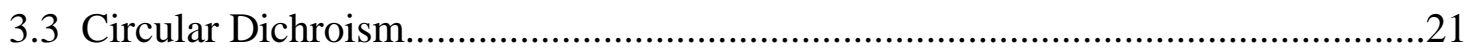

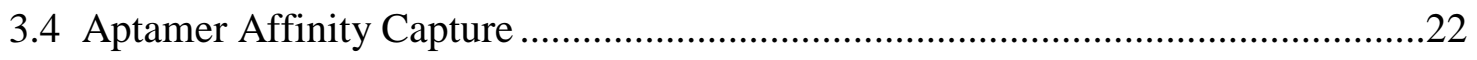

3.4.1 Magnetic Bead Activation ...................................................................22

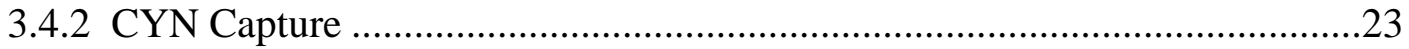

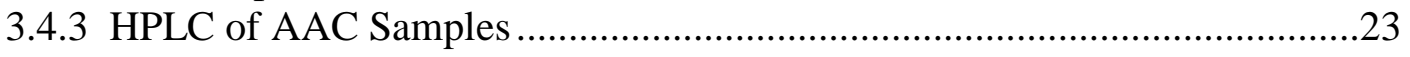

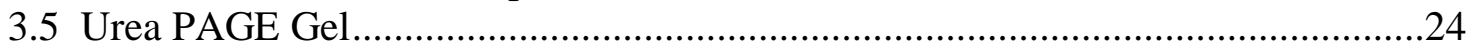

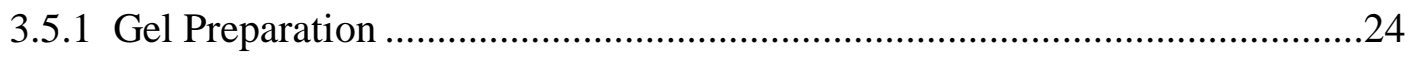

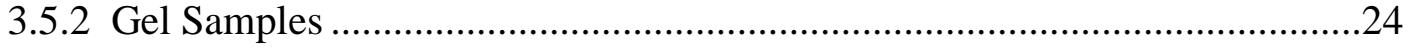

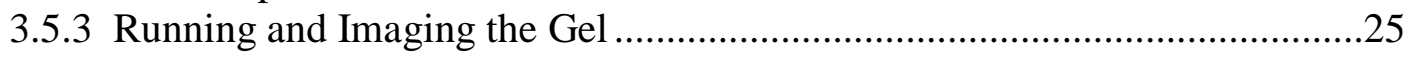

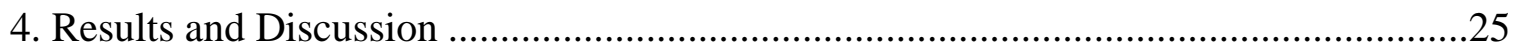

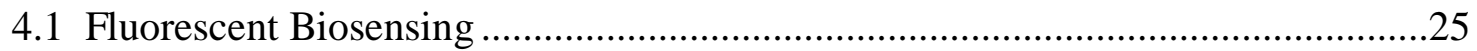

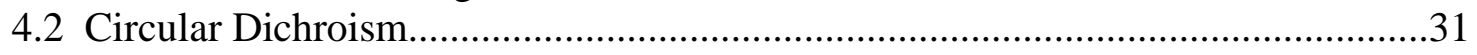

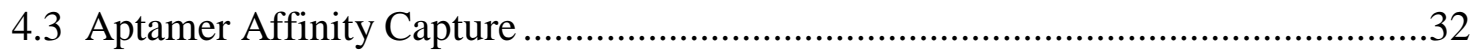

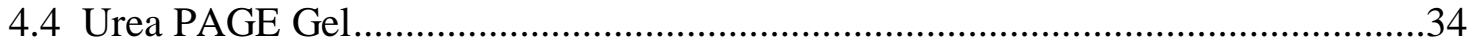

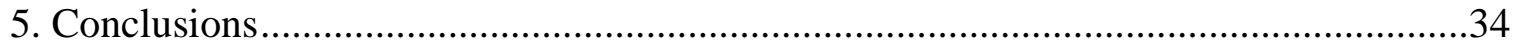




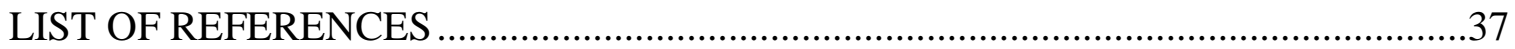




\section{LIST OF TABLES}

TABLE

PAGE

1. Advantages and Disadvantages of Antibodies in Detecting Target Molecules .............5

2. Advantages and Disadvantages of Aptamers in Detecting Target Molecules ..............6

3. Applications of aptamers in the analysis of the target molecules ..............................12

4. Time program for HPLC purification of CYN ..................................................19

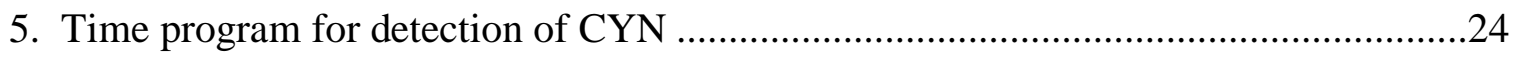




\section{LIST OF FIGURES}

FIGURE

PAGE

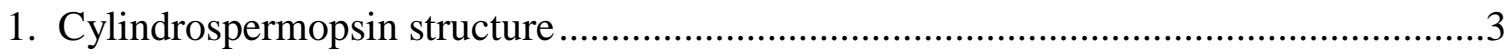

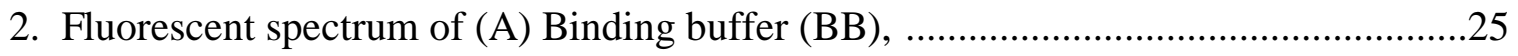

(B) $\mathrm{CYN}$ in BB, (C) Aptamer in BB, (D) Aptamer in BB (top) $100 \mathrm{uM} \mathrm{CYN}$ and Aptamer in BB (middle) and $500 \mathrm{uM} \mathrm{CYN}$ and Aptamer in BB (bottom)

3. Fluorescence spectrum of Aptamer in BB and after .26 the addition of $10 \mathrm{uM} \mathrm{CYN} \mathrm{(10} \mathrm{uM),} 25 \mathrm{uM} \mathrm{CYN}$ (25 uM), $50 \mathrm{uM} \mathrm{CYN} \mathrm{(50} \mathrm{uM),} 75$ uM CYN (75 uM), and $100 \mathrm{uM} \mathrm{CYN} \mathrm{(100} \mathrm{uM).}$

4. Fluorescent spectrum of aptamer after the addition .26 100 uM Microcystin-LR (MC-LR), 100 uM BMAA (BMAA), and $100 \mathrm{uM} \mathrm{CYN} \mathrm{(CYN)}$

5. Percent Gain of CYN with five different fluorescent probes

6. Percent Gain of CYN using QuantiFluor dsDNA probe 27

7. Reproducibility of Percent Gain of CYN using QuantiFluor dsDNA probe ...............28

8. Reproducibility of Percent Gain of MC-LR using QuantiFluor dsDNA probe...........28

9. Reproducibility of Percent Gain of BMAA using QuantiFluor dsDNA probe ....

10. Comparison of Percent Gain of the three toxins with QuantiFluor dsDNA probe .....29

11. CD spectrum of (A) $1 \mathrm{uM}$ aptamer before and after the addition of $2 \mathrm{uMCYN}$ performed by Elshafey et al. [33] and (B) $1 \mathrm{uM}$ aptamer before and after the addition of $2 \mathrm{uM} \mathrm{CYN}$

12. Chromatogram of (A) supernatent after incubation 32 with beads, (B) 75 uM CYN standard, (C) supernatant after elution with Milli-Q ${ }^{\circledR}$ water, (D) supernatant after wash with BB 
13. (A) Urea PAGE Gel of DNA ladder (1), Aptamer (2), Aptamer and CYN (3), Aptamer and MC-LR (4), Aptamer and BMAA (5), and DNA Ladder (6), (B) inverse of gel (A) 
ACRONYMS AND ABBREVIATIONS

\begin{tabular}{|c|c|}
\hline $\mathrm{AAC}$ & Aptamer Affinity Capture \\
\hline $\mathrm{ACN}$ & Acetonitrile \\
\hline APS & Ammonium persulfate \\
\hline BB & Binding buffer \\
\hline BMAA & $\beta$-Methylamino-L-alanine \\
\hline CYN & Cylindrospermopsin \\
\hline EDC & $\begin{array}{l}\text { N-Ethyl-N'-(3-dimethylaminopropyl) } \\
\text { carbodiimide hydrochloride }\end{array}$ \\
\hline FA & Formic Acid \\
\hline HPLC & High Performance Liquid Chromatography \\
\hline MC-LR & Microcystin-LR \\
\hline $\mathrm{MeOH}$ & Methanol \\
\hline MES & $\begin{array}{l}\text { 2-(N-Morpholino)ethanesulfonic acid } \\
\text { hydrate }\end{array}$ \\
\hline Milli-Q® & Ultra-pure water \\
\hline PAGE & Polyacrylamide gel electrophoresis \\
\hline SPE & Solid phase extraction \\
\hline TEMED & N,N,N',N',-Tetramethylethylenediamine \\
\hline TFA & Trifluoroacetic acid \\
\hline UFLC & Ultra Fast Liquid Chromatography \\
\hline UV & Ultra violet \\
\hline
\end{tabular}




\section{Introduction}

\subsection{Cyanobacteria}

Cyanobacteria are prokaryotic organisms that synthesize chlorophyll a through photosynthesis. Most of these organisms are aquatic, using water as the electron donor for oxygen production. Though aquatic in nature, cyanobacteria exist in a wide range of environments. Cyanobacteria thrive particularly in warmer environments and can withstand high salt concentrations. Ultra-violet (UV) conditions vary greatly in environments inhabited by cyanobacteria. These organisms can utilize UV light even in low light density conditions which makes cyanobacteria resilient organisms [1].

Cyanobacteria are often called "blue-green algae" because of their production of blue pigments [1]. Blue-green algae can form in blooms in aquatic environments, forming a covering over bodies of water. The algal blooms can affect the environments below the blooms and main water supplies by decreasing the amount of sunlight that can reach photosynthetic species below the surface. The amount of dissolved oxygen in the water decreases because the bloom does not allow for a flow of oxygen from the surface. The blooms can hinder the filtering and purification of water that is used to supply homes and businesses. Another issue these bloom-forming species of cyanobacteria pose is that many of them are considered to be toxin producing. These species produce cyanobacterial toxins that can be harmful to the environment and other species including humans through the food chains and biomagnification [2]. 


\subsubsection{Cyanobacterial Toxins}

Cyanobacterial toxins or cyanotoxins are an increasing problem in aquatic environments. Cyanotoxins are produced by cyanobacteria and can be released in to the water systems where there is presence of blue-green algae. There are 40 different species of cyanobacteria that are believed to produce some form of cyanotoxin. These toxins are categorized in to four groups. The four groups are: hepatotoxins, neurotoxins, endotoxins

and general cytotoxins. The general cytotoxins do not have a targeted system as the other groups do. The general cytotoxins can affect one or multiple organs making it more difficult to treat an exposure [2] .

Cyanotoxins not only affect freshwater and marine organisms, they also pose a risk to humans. These toxins reach humans through contamination of drinking water or where humans come into contact with water such as lakes and oceans [3-5]. Water sources are an optimal source for algal bloom growth as a result of pollution from pharmaceuticals and fertilizers. The pollution proves an abundance of nutrients that support algal blooms. Cyanotoxins can persist in water even after the bloom has died off. The persistence results in bioaccumulation which can lead to biomagnification [6]. Biomagnification is the process of toxins being transferred in increasing concentrations from organisms lower on the food chain to an organism higher on the food chain. Animals can have high concentrations of toxins in their system from ingesting their food source. Animals can also become exposed to these toxins by their water intake. Animals drink from water sources that are untreated and unfiltered. Humans are less likely to become exposed to cyanotoxins through their water supply if they have access to filtered 
and treated drinking water but contaminated water sources that are used for recreational purposes such as lakes and oceans can lead to exposure. [2]

Contamination of water supplies had caused a growing need for the improvement of detection methods for toxins [6]. Since the toxins can have toxicity levels detrimental to human health, it is important to determine the quality of the water being used by both humans and wildlife. Detection of cyanotoxins has been performed using a multitude of methods. High performance liquid chromatography (HPLC), liquid chromatographymass spectrometry (LCMS), mouse bioassay, protein phosphatase bioassay, and enzymelinked immunosorbent assay (ELISA) have all been used to detect cyanotoxins. These methods have often been used as a tool in determining safe drinking levels of toxins in water [7].

\subsection{Cylindrospermopsin}

The toxin investigated in this work was cylindrospermopsin (CYN).

Cylindrospermopsin is a cyanotoxin produced by multiple species of cyanobacteria.

The toxin is an alkaloid with a cyclic guanidine group. CYN is a water soluble molecule making it easy to contaminate water systems.

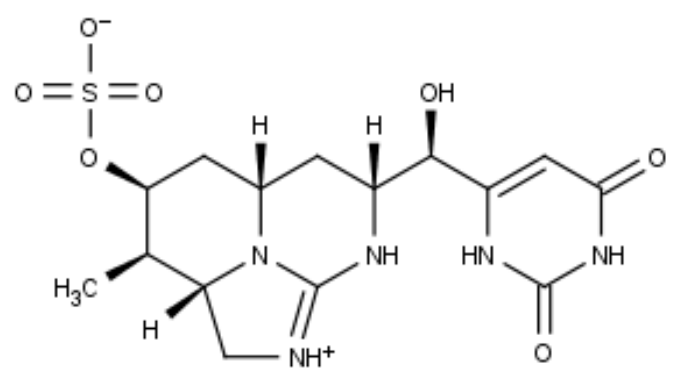

Figure 1. Cylindrospermopsin structure [8] 
It was first reported as having toxic effects in a study done in Australia in the 1980s. Hundreds of children were brought to hospitals in Australia with gastrointestinal symptoms. These symptoms were linked to blooms of Cylindrospermopsis raciborskii in the water supply. The incident was the first to show that CYN can affect human health [9]. Cylindrospermopsin is known to affect the liver, heart, gastrointestinal tract and has also been studied as having genotoxic effects [10]. It acts as a protein synthesis inhibitor but the mechanism is unknown. The protein synthesis inhibition causes many of the symptoms of this toxin [11-13]. Cylindrospermopsin has been reported in areas all over the world with evidence of algal blooms in those areas [14-15]. The abundance of the algal blooms and the toxic effects are what make CYN an important topic of research.

High performance liquid chromatography (HPLC) and liquid-chromatography mass-spectrometry ((HP)LC-MS) have been the primary methods utilized for CYN detection. HPLC and (HP)LC-MS have allowed for accurate detection but there is difficulty distinguishing between chiral molecules and molecules with similar masses. [16] The instruments required for these analyses are expensive and require a high level of sample purity. [16-17] Enzyme-linked immunosorbent assay, ELISA, has been used in the analysis of CYN but is also an expensive analytical tool [18]. The ELISA method uses antibodies to detect and quantify the presence of CYN. Antibodies have both advantages and disadvantages to their use as seen in Table 1. Aptamers are a new and emerging technique that address the disadvantages of antibodies and provide an inexpensive alternative. 
Table 1. Advantages and Disadvantages of Antibodies in Detecting Target Molecules [19]

\begin{tabular}{|c|c|}
\hline Advantages & Disadvantages \\
\hline $\begin{array}{l}\text { - Pharmacokinetic and other systemic } \\
\text { properties of antibodies are often } \\
\text { sufficient to support product } \\
\text { development } \\
\text { - Large size prevents renal filtration } \\
\text { and together with binding to neonatal } \\
\text { Fc receptors can give extended } \\
\text { circulating half-lives } \\
\text { - Not susceptible to nuclease } \\
\text { degradation } \\
\text { - Antibody technologies are widely } \\
\text { distributed because the early } \\
\text { intellectual property either never } \\
\text { existed or has expired }\end{array}$ & $\begin{array}{l}\text { - Antibodies are produced biologically in a } \\
\text { process that is difficult to scale up without } \\
\text { affecting product characteristics -Viral or } \\
\text { bacterial contamination of manufacturing } \\
\text { process can affect product quality } \\
\text { - Often immunogenic } \\
\text { - Large size limits bioavailability or } \\
\text { prevents access to many biological } \\
\text { compartments } \\
\text { - Limited ability to utilize negative selection } \\
\text { pressure or to select against cell-surface } \\
\text { targets not available in functional } \\
\text { recombinant form } \\
\text { - Susceptible to irreversible denaturation; } \\
\text { limited shelf life } \\
\text { - Chemistries required for the attachment of } \\
\text { conjugation partners are stochastic and lead } \\
\text { to product mixtures and reduced activity }\end{array}$ \\
\hline
\end{tabular}

\subsection{DNA Aptamers}

An aptamer is a strand of nucleic acids that when folded into its three-dimensional structure binds to a target molecule. The use of an aptamer in an analytical method to test biological samples not only allows for detection of the toxin, but also for accurate quantification [20-21]. The use of aptamers has advantages over other analytical methods such as ELISA. Aptamers, as nucleic acids, are more chemically stable than antibodies with comparable specificity. They can be selected for different types of molecules such as toxins and proteins and can also be produced in large quantities with 
high purity [22-24]. These advantages make aptamers an attractive addition to analytical methods of analysis. Aptamer-based methods, like any analytical method, do have disadvantages (Table 2), but the disadvantages can be addressed to maximize the effectiveness of the aptamers.

Table 2. Advantages and Disadvantages of Aptamers in Detecting Target Molecules [19]

\begin{tabular}{|l|l|}
\hline Advantages & Disadvantages \\
\hline - Aptamers are produced chemically in & - Pharmacokinetic and other systemic \\
p readily scalable process & prerties are variable and often hard to \\
- Chemical production process is not & - Small size makes them susceptible to renal \\
prone to viral or bacterial & filtration and they therefore have a shorter \\
contamination & half-life \\
- Non-immunogenic & - Unmodified aptamers are highly susceptible \\
- Smaller size allows more efficient & to serum degradation \\
entry into biological compartments & - Aptamer technologies are currently largely \\
- Able to select for and against & covered by a single intellectual property \\
specific targets and to select against & portfolio \\
cell-surface targets & \\
- Can usually be reversibly denatured, \\
and phosphodiester bond is extremely \\
chemically stable
\end{tabular}

Aptamers can be identified for specific targets using a method called systematic evolution of ligands by exponential enrichment (SELEX). The method was developed in 1990. The SELEX method uses multiple steps to identify aptamer candidates for the selected target. An oligonucleotide library is used to find multiple candidates that bind to the target. [25] Typically, the library consists of nucleic acid molecules ranging from 60mers to 96-mers with random sequences and constant primer sequences [26]. The library 
is mixed with an immobilized target, and unbound oligonucleotides are removed. The bound oligonucleotides are the aptamer candidates. The candidates are removed from the target and amplified using PCR. These steps are repeated multiple times to identify a candidate. The aptamer is sequenced so that it can be synthesized for use. Once an aptamer is sequenced, it can be reproduced in large quantities [25, 27].

The SELEX method has been adapted to work with a wide variety of molecules making it very useful in areas where other methods, such as using antibodies, are not an option. Improved variations of the SELEX method allows for discrimination between the most strongly bound aptamers, and more weakly bound candidates, that would not be effective for the target. SELEX variations include signaling aptamers which change structure and produce a signal when bound to the target, and negative SELEX which removes aptamers that bind to similar molecules first, leaving a smaller, more specific oligonucleotide pool to select from $[25,28,29]$.

With small molecules like CYN, there are challenges to identifying an aptamer. SELEX requires the immobilization of the target. Small molecules have inherently less functional groups than large molecules. These functional groups are used to bind the target to a stationary phase. Any modification of the target to allow for immobilization could alter the effectiveness of the aptamer to bind to the original unmodified target. Small molecules will be in a lower ratio to the column matrix. With an abundance of column ratio, the chance of non-specific binding aptamer candidates increases. The binding affinity of the target to the aptamer is a major requirement in determining the effectiveness of the aptamer. Many methods for determining the binding affinity require 
an obvious change in signal. Methods such as HPLC or capillary electrophoresis require a difference in size and may be less useful if the target is small because the free aptamer and the target-aptamer complex may co-elute. Other methods rely on a change in fluorescence of the target and the target-aptamer complex, but this change in signal would only occur if the target has fluorescent properties. A fluorescent probe would be required if the target itself does not have fluorescent properties such as CYN. Though faced with many challenges, the identification and use of aptamers for small molecules hold many opportunities for understanding key biological and chemical mechanisms. Aptamers can detect the presence of small drug molecules, such as cocaine, or biological molecules such as ATP or intracellular proteins. As an example, a dopamine-specific aptamer was used to isolate excess dopamine in the brain and determine whether this removal of dopamine from a part of the brain causes a correction of abnormal brain activity [30].

Aptamers can also be helpful and effective in detecting the presence of foreign molecules. Since the development of SELEX and aptamers, there have been hundreds of aptamers identified. There has been research done on multiple types of targets such as inorganic components, small organic molecules, antibiotics, and toxins [31] . In fact, aptamers for multiple cyanotoxins have been studied. The cyanotoxin, microcystin, has an identified aptamer that is continuing to be studied for various applications [32]. Elshafey et al. identified an aptamer for CYN using SELEX. The authors performed binding studies using circular dichroism and fluorescence. The binding constant of the DNA aptamer for CYN was reported as $88.78 \mathrm{nM}$. Once the binding was established, the 
authors designed an impedimetric aptasensor with the aptamer immobilized on a gold plate. The change in signal of the sensor was used to detect the presence of CYN in water samples with known concentrations of CYN and tap water samples spiked with CYN. The authors reported accuracies of $95.8 \%$ to $103.2 \%$ [33].

\subsection{Circular Dichroism}

Light can be circularly polarized wherby the light wave moves in either a clockwise (right-handed) or counterclockwise (left-handed) direction. These light waves can be absorbed by a chiral chromophore, or an asymmetrical light-absorbing group. Circular dichroism (CD) is the difference between the absorbances of the clockwise and counterclockwise light. The difference is measured using CD spectroscopy. The CD spectrum of a sample is determined by measuring the differences in absorbance over multiple wavelengths. The structure of a molecule determines the spectrum so CD spectroscopy can identify the secondary structures of proteins and DNA. This is especially helpful in determining a conformational change in DNA when in the presence of the target molecule [34].

The CD spectroscopy of multiple DNA duplexes and anticancer drugs pairs was reviewed by Yu-Ming Chang et al [35]. They used the CD data to discuss the conformational changes of the DNA duplexes observed after exposure to the anticancer drugs. The conformational change of the DNA is important for improving the anticancer drugs to make them more target-specific with fewer undesirable reactions [35]. Circular dichroism spectroscopy was also used to determine the conformational change of the aptamer for CYN when in the presence of the toxin. In this experiment, CD was used to 
investigate if a conformational change occurs, and what form the DNA takes after the conformational change [33].

\subsection{Fluorescent Biosensing}

Fluorescent spectroscopy is a commonly used technique in analyzing organic compounds. Fluorescent probes can be used to label compounds that do not have fluorescent properties on their own. Biosensing is the use of DNA, antibodies, or enzymes to detect the presence of biological or chemical molecules. Fluorescence biosensing uses changes in fluorescence to determine the presence of a target molecule. The fluorescence can be from the target molecule's own fluorescent properties, a fluorescent label, or a fluorescent probe. Label-free fluorescence biosensing is a technique that has been studied as a solution to detecting molecules without fluorescent properties, and without having to label the aptamers or target molecules with a probe, that would potentially alter their chemical properties [36]. Fluorescent probes are widely available and some of the probes have greater fluorescence when they bind to aptamers. Cylindrospermopsin does not have fluorescent properties so a label free method would be an ideal technique in determining the presence of CYN with the aptamer.

\subsection{Aptamer Affinity Chromatography}

Aptamer affinity chromatography (AAC) was first reported in 1999 by Drolet et al. as a means of protein purification [37]. Aptamer affinity chromatography requires the immobilization of a DNA aptamer to a stationary phase. The aptamer is exposed to the target molecule in solution and then the target molecule can be separated from the 
aptamer and its original solution. There are many applications of AAC that provide chromatographic techniques of detection, separation, and purification. Aptamers can be immobilized on different types of beads such as magnetic beads or streptavidin-modified beads, and then packed in to a column for analysis. Solid phase extraction can be made possible with an aptamer that allows for purification of target molecules. Microfluidic devices have been used to separate and detect target molecules using aptamers. These techniques can be useful for small molecules, proteins and whole cells. Examples of the uses of AAC and their targets can be seen in Table 3 [38]. 
Table 3. Applications of aptamers in the analysis of the target molecules [38]

\begin{tabular}{|l|l|l|l|}
\hline Target & Aptamer & Stationary Phase & Application \\
\hline Adenosine & DNA & Packed capillary column & Detection \\
\hline ATP & DNA & Hydrogel & Purification \\
\hline Ochratoxin A & DNA & Resins packed SPE column & Extraction and Offline detection \\
\hline Cocaine & DNA & Graphene oxide & Extraction and Detection \\
\hline Arsenic & DNA & Agarose resin & Removal \\
\hline Thrombin & DNA & Bead-packed column & Purification \\
\hline Histone proteins & DNA & Bead-packed spin column & Preconcentration \\
\hline His-tagged proteins & DNA & Magnetic beads & Purification \\
\hline Thyroid transcription factor 1 & DNA & Magnetic beads & Purification \\
\hline Prostate cancer cells & RNA & Microfluidic device & Capture, enumeration \\
\hline Glioblastoma & RNA & Microfluidic device & Capture \\
\hline Salmonella typhimurium & DNA & Magnetic beads & Preconcentration, detection \\
\hline
\end{tabular}




\subsection{Specific Aims}

This study aimed to confirm the binding of the aptamer to CYN. The binding was investigated using fluorescent biosensing and CD. Since the Elshafey group performed CD [33], the CD data from this study was performed to compare to the Elshafey CD data to confirm binding. The fluorescent biosensing was performed to observe a change in signal indicative of the aptamer binding to the CYN.

The second aim of this study was to determine if the CYN aptamer could have a real world application in the form of an aptamer affinity capture method. Magnetic beads were used to immobilize the aptamer for incubation with CYN. High performance liquid chromatography was used to determine if the CYN bound to the beads and if CYN could be eluted off he beads.

\section{Materials}

\subsection{Purification of CYN}

The algal cultures used in the purification of CYN were grown by Dr. Gantar's lab at FIU. The algal cultures were grown in BG-11 medium, modified from Rippka et al [39]. The $\mathrm{pH}$ of the medium was adjusted to 7.0 with $\mathrm{NaOH}$. The medium was autoclaved at $121^{\circ} \mathrm{C}$ for $15 \mathrm{~min}$ before use. The $\mathrm{pH}$ was further adjusted to $7.4 \mathrm{using}$ $\mathrm{NaOH}$ after autoclaving. The BG-11 medium used for the growing cycles was run through a $0.22 \mu \mathrm{m}$ Millipore syringe filter. The cultures were grown under a $40 \mathrm{~W}$ neon lamp for $24 \mathrm{~h}$. An incubation temperature of $27-30^{\circ} \mathrm{C}$ was used for the growing cycles [39]. 
HPLC-grade water and acetonitrile were purchased from Fisher Scientific (Thermo Fisher Scientific, Fair Lawn, NJ). HPLC-grade methanol was purchased from EMD Millipore Corporation (Billerica, MA). Formic acid was purchased from Fluka Analytical Sigma-Aldrich (Chemie Gmbh, Steinhein, Germany). Trifluoroacetic acid was purchased from J.T. Baker, Mallinckrodt Baker Inc. (Phillipsburg, NJ). Chitosan was purchased from Sigma Aldrich (St. Louis, MO). A WaterPro PS Milli-Q® water system (Labconco, Kansas City, MO) was used to obtain the Milli-Q® water used in the purification. The filters used were Millipore Nitrocellular $\mathrm{MF}^{\mathrm{TM}} 0.45 \mathrm{um} \mathrm{HA}, 47 \mathrm{~mm}$, non-sterile filter and Millipore Nylon Membrane 0.20um, 47mm, non-sterile filter purchased from Merck Millipore Ltd. (Tullagreen, Cork, Ireland). The SPE cartridge used was ExtractClean ${ }^{\mathrm{TM}}$ Carbo $300 \mathrm{mg} / 8 \mathrm{~mL}$ purchased from Grace Davidson Discovery Science (Deerfield, IL). Falcon ${ }^{\mathrm{TM}} 50 \mathrm{~mL}$ conical centrifuge tubes, HPLC vials $(2.0 \mathrm{~mL}$, amber), and scintillation vials (20 mL, borosilicate glass) were purchased from Fisher Scientific (Thermo Fisher Scientific, Fair Lawn, NJ).

\subsection{Fluorescent Biosensing}

The CYN purified in 3.1 and a CYN standard (1 mg) purchased from Enzo Life Sciences (Farmingdale, NY) was used for this experiment. L-BMAA hydrochloride and microcystin-LR standards were purchased from Sigma Aldrich (St. Louis, MO). The binding buffer was made with $50 \mathrm{mM}$ Tris, $\mathrm{pH} 7.5,20 \mathrm{mM} \mathrm{MgCl} 2$ and $150 \mathrm{mM} \mathrm{NaCl}$. The TRIZMA ${ }^{\circledR}$ hydrochloride reagent grade (Tris) and $\mathrm{NaCl}$ was purchased from Sigma Lifescience (Sigma-Aldrich, St Louis, MO). The $\mathrm{MgCl}_{2} 6$ hydrate crystal was purchased from J.T. Baker (Mallinckrodt Baker Inc., Phillipsburg, NJ) [33] The DNA aptamer (5' 
amino modification, 6 carbon linker, HPLC purified) was purchased from Integrated DNA Technologies (IDT)(Coralville, IA) using the DNA sequence from Elshafey et al. [33]. The fluorescent probes Quantifluor double strand and single strand were purchased from Promega (Madison, WI). The probes SYBR Gold, SYBR Green, and Oligreen were purchased from Invitrogen (Thermo Fisher Scientific, Carlsbad, CA). A 10 mm quartz cuvette was used for measurements as discussed in 3.2.

\subsection{Circular Dichroism}

The CYN purified in 3.1 was used for this experiment. The BB used in 2.2 was also used in this experiment [33]. The DNA aptamer (5' amino modification, 6 carbon linker, desalted) was purchased from Integrated DNA Technologies (IDT)(Coralville, IA) using the DNA sequence from Elshafey et al. [33]. A $10 \mathrm{~mm}$ quartz cuvette was used for measurements as discussed in 3.3.

\subsection{Aptamer Affinity Capture}

The Dynabeads M-270 Carboxylic Acid magnetic beads were purchased from Invitrogen (Thermo Fisher Scientific, Carlsbad, CA). The BB used in 2.2 was also used in this experiment. The EDC and MES buffer for activation were purchased from Sigma Lifescience (Sigma-Aldrich, St Louis, MO). The DNA aptamer (5' amino modification, 6 carbon linker, HPLC purified) was purchased from Integrated DNA Technologies (IDT)(Coralville, IA) using the DNA sequence from Elshafey et al. [33]. The CYN standard (1 mg) was purchased from Enzo Life Sciences (Farmingdale, NY). A WaterPro PS Milli-Q® water system (Labconco, Kansas City, MO) was used to obtain 
the Milli-Q® water used in this experiement. The magnet used was a Neodymium rectangular block magnet. Eppendorf ${ }^{\mathrm{TM}}$ Microcentrifuge tubes were purchased from Fisher Scientific (Fair Lawn, NJ).

\subsection{Urea PAGE Gel}

The urea, APS, TEMED, and acrylamide (40\% w/v) were purchased from Fisher Scientific (Thermo Fisher Scientific, Fair Lawn, NJ). The 5X TBE buffer consisted of $445 \mathrm{mM}$ Tris base, $445 \mathrm{mM}$ boric acid and $10 \mathrm{mM}$ EDTA, all purchased from Fisher Scientific (Thermo Fisher Scientific, Fair Lawn, NJ). The DNA aptamer (5' amino modification, 6 carbon linker, HPLC purified) was purchased from Integrated DNA Technologies (IDT)(Coralville, IA) using the DNA sequence from Elshafey et al. [33]. The DNA ladder consisted of DNA fragments (11, 14,17, 20, 23, 26, 29, 32, 35, $38 \mathrm{nt})$ purchased from Integrated DNA Technologies (IDT)(Coralville, IA). The fluorescent probes Quantifluor double strand was purchased from Promega (Madison, WI). The CYN standard (1 mg) was purchased from Enzo Life Sciences (Farmingdale, NY). LBMAA hydrochloride and microcystin-LR standards were purchased from Sigma Aldrich (St. Louis, MO). Xylene cyanol FF (Sigma Lifescience Sigma-Aldrich, St Louis, MO).

\section{Experimental}

\subsection{Purification of CYN}

The culture was prepared and purified used a method that was previously modified [40-42]. The method is briefly described below. 


\subsubsection{Pretreatment of Culture Medium and Biomass}

The culture was transferred to four $500 \mathrm{~mL}$ centrifuge bottles; each bottle contained $300 \mathrm{mLs}$ of the culture. Chitosan was added at a volume of $10 \mathrm{~mL}$ to each bottle. The bottles were centrifuged for $20 \mathrm{~min}$ at $4000 \mathrm{rpm}$ using a Beckman Coulter Allegra X-15R centrifuge. The clarified culture medium (supernatant) was poured off, leaving around $20 \mathrm{~mL}$ of supernatant at the bottom of the bottle, in to multiple 1 liter bottles, and refrigerated for later use. The remaining volume of supernatant left in the bottle was used to resuspend the biomass layer on the bottom of the bottle. The contents of the bottle were then transferred to several $50 \mathrm{~mL}$ falcon tubes. Chitosan was added at a volume of $2 \mathrm{~mL}$ to each tube. The tubes were centrifuged with the same parameters described above. The medium was transferred into the $1 \mathrm{~L}$ bottles (with previously collected culture medium) and the biomass in the tubes was immediately frozen at $-20^{\circ} \mathrm{C}$.

Once frozen, the biomass was lyophilized in the falcon tubes using a Labconco Freezone Cascade Benchtop Freeze Dry System, and kept in $-20^{\circ} \mathrm{C}$ for later use.

\subsubsection{Extraction of CYN from Culture Biomass}

The lyophilized biomass was weighed out to $2.0 \mathrm{~g}$, and re-suspended in $200 \mathrm{~mL}$ of Milli-Q® water in a $500 \mathrm{~mL}$ Erlenmeyer flask. The solution was left to sit for $24 \mathrm{~h}$ to allow for full resuspension of the cells. The solution was then transferred to two $200 \mathrm{~mL}$ Erlenmeyer flasks with $100 \mathrm{~mL}$ of Milli-Q ${ }^{\circledR}$ water in each flask. The two flasks were then sonicated in an ultrasonic bath for two 5 min periods. The flasks were swirled in between each 5 min period. The biomass was then filtered in a vacuum filtration apparatus using a 0.45 micrometer membrane filter. When the biomass was filtered, 5 
$\mathrm{mL}$ of Milli-Q ${ }^{\circledR}$ water was put through the filter to rinse the filter apparatus. The filtrate was then filtered using a 0.20 micrometer membrane filter. The apparatus was rinsed with another $5 \mathrm{~mL}$ of Milli-Q ${ }^{\circledR}$ water. The filtrate was transferred to a carbograph SPE cartridge and filtered using a vacuum manifold. The cartridge was pretreated with 3.0 $\mathrm{mL}$ of $5 \% \mathrm{FA}$ in $\mathrm{MeOH}$ followed by $3.0 \mathrm{~mL}$ of Milli-Q® water. After the filtrate had passed through the cartridge, it was washed with $0.5 \mathrm{~mL}$ of methanol. Following the washing step, $20 \mathrm{~mL}$ of $5 \% \mathrm{FA}$ in $\mathrm{MeOH}$ was run through the cartridge, as the eluent, and collected in a scintillation vial. The eluent was dried down using a rotating evaporator and the sample was re-suspended in $250 \mu \mathrm{L}$ of Milli-Q® water. The sample was then stored in $4^{\circ} \mathrm{C}$ in a $2.0 \mathrm{~mL}$ glass vial until analysis.

\subsubsection{Extraction of CYN from Culture Medium}

The previously prepared (i.e., centrifuged) culture medium was transferred in to $500 \mathrm{~mL}$ centrifuge bottles and centrifuged at $4000 \mathrm{rpm}$ for $20 \mathrm{~min}$. The supernatant was subsequently filtered by vacuum through a $0.2 \mu \mathrm{m}$ membrane filter. The filtrate was passed through a carbograph SPE cartridge and filtered using a vacuum manifold. The cartridge was pretreated with $3.0 \mathrm{~mL}$ of 5\% FA in $\mathrm{MeOH}$ followed by $3.0 \mathrm{~mL}$ of Milli$\mathrm{Q}{ }^{\circledR}$ water. After the filtrate had passed through the cartridge, it was washed with $0.5 \mathrm{~mL}$ of methanol. Following the washing step, $20 \mathrm{~mL}$ of $5 \% \mathrm{FA}$ in $\mathrm{MeOH}$ was run through the cartridge, as the eluent, and collected in a scintillation vial. The eluent was dried down using a Buchi R-3 rotating evaporator and the sample was re-suspended in $250 \mu \mathrm{L}$ of Milli-Q ${ }^{\circledR}$ water. The sample was then stored in $4^{\circ} \mathrm{C}$ in a $2.0 \mathrm{~mL}$ glass vial until analysis. 


\subsubsection{HPLC Purification}

Final purification and analysis of CYN was performed on a Shimadzu Prominence modular UFLC. A Luna 5u C18 100A, 250 x 4.60 mm, 5 micron column was used. The injection volume of the sample was $10 \mu \mathrm{L}$ and the sample was monitored at $262 \mathrm{~nm}$. The mobile phase consisted of $0.1 \%$ TFA in HPLC water (A) and $0.1 \%$ TFA in $\mathrm{ACN}(\mathrm{B})$. The flow rate was $1 \mathrm{~mL} /$ minute. The gradient method is listed in Table 4. The chromatograph and UV spectrum was monitored to observe the peak with the UV spectrum that corresponds with CYN. The mobile phase exiting the HPLC (fraction) is collected in a scintillation vial immediately after the CYN peak is observed. The sample run is repeated until the medium or biomass sample is completely utilized. The fractions are collected in the same scintillation vial. The fractions were dried using the rotating evaporator to obtain solid CYN material.

Table 4. Time program for HPLC purification of CYN

\begin{tabular}{|c|c|c|}
\hline Time (min) & \% of Solvent A & \% of Solvent B \\
\hline $0-30$ & $100-92$ & $8-8$ \\
\hline $30-32$ & $92-100$ & 0 \\
\hline $32-35$ & 100 & \\
\hline
\end{tabular}




\subsection{Fluorescent Biosensing}

\subsubsection{Fluorimeter}

Control samples of binding buffer, 1X SYBR Green, $10 \mathrm{uM}$ aptamer and $100 \mu \mathrm{M}$ CYN were run to determine if the samples contributed a fluorescent signal. The probe was added to the aptamer, with final concentrations of $1 \mathrm{X}$ and $10 \mathrm{uM}$, respectively. The sample was analyzed to obtain a baseline of the fluorescent signal. The CYN was added to samples of the SYBR Green and the aptamer at varying final concentrations $(10 \mu \mathrm{M}$, $25 \mu \mathrm{M}, 50 \mu \mathrm{M}, 75 \mu \mathrm{M}, 100 \mathrm{uM}, 350 \mathrm{uM}$, and $500 \mathrm{uM})$. All samples had a final volume of $1.2 \mathrm{~mL}$.

The Horiba Fluoromax-3 fluorimeter was used to measure the fluorescent signal of the samples. The emission was set to scan from 500 to $650 \mathrm{~nm}$ and the excitation was set to $497 \mathrm{~nm}$. The signal was averaged from a total of three scans set at the fast scan

mode. A quartz cuvette with a $10 \mathrm{~mm}$ path length was used to measure the fluorescence.

\subsubsection{Tecan Plate Reader}

A super mix was made consisting of a 1.1X mixture of the DNA aptamer and BB. A 1.05X ultra mix of fluorescent probe (SYBR Gold, SYBR Green, Oligreen, QuantiFluor double strand or QuantiFluor single strand) and the super mix was created. An aliquot of the ultra mix was added to $100 \mu \mathrm{M}$ of the target (CYN, MC-LR, or BMAA) at a final volume of $100 \mu \mathrm{L}$ for the Tecan sample. The final concentration in the sample was $1 \mathrm{X}$ fluorescent probe, $1 \mu \mathrm{M}$ DNA aptamer and $100 \mu \mathrm{M}$ target. The sample was 
transferred in to the plate with $95 \mu \mathrm{L}$ of sample in each well. A control sample of aptamer, fluorescent probe, and BB was run with the samples.

The Tecan Infinite M1000 Pro was used to expand on the fluorimeter data using different probes with smaller volumes. The samples were analyzed first to obtain the gain and $\mathrm{Z}$ position calculated from the control sample. The excitation and emission values were set according the fluorescent probe in the sample. The samples were then analyzed with a manually entered gain and $\mathrm{Z}$ position of each fluorescent probe from the first analysis. The percent gain was calculated from the results of the samples compared to the results of the control.

\subsection{Circular Dichroism}

All samples were prepared in binding buffer with final volumes of $1.2 \mathrm{~mL}$. Samples of binding buffer and $2 \mathrm{uM} \mathrm{CYN}$ were used to obtain background signals. Spectrum of a $1 \mathrm{uM}$ sample of the aptamer was measured and compared to the spectrum of a $1 \mathrm{uM}$ of the aptamer after addition of $2 \mathrm{uM} \mathrm{CYN}$. Samples were analyzed in a quartz cuvette with a $10 \mathrm{~mm}$ path length.

A Jasco J-815 Circular Dichroism Spectrometer was used to measure the structural conformation of the samples. The measurements were made from 230 to 340 $\mathrm{nm}$ at a $0.1 \mathrm{~nm}$ interval. Three scans were performed at $20 \mathrm{~nm} / \mathrm{min}$ with a $1 \mathrm{~nm}$ bandwidth and a $1 \mathrm{sec}$ time constant. Nitrogen was used to deoxygenate the optical chamber and was maintained throughout the duration of the experiment. 


\subsection{Aptamer Affinity Capture}

\subsubsection{Magnetic Bead Activation}

Magnetic beads (Dynabeads) were used as the solid phase for AAC. The beads were activated following a modified Thermo Scientific protocol. A volume of $100 \mathrm{uL}$ of the beads was transferred to an Eppendorf tube. A magnet was applied for two minutes and the supernatant was removed. The beads were washed with $100 \mathrm{uL}$ of $25 \mathrm{mM}$ MES buffer, $\mathrm{pH}$ 5, for $10 \mathrm{~min}$ on a Stuart SB3 rotator. The magnet was applied to the tube for two minutes and the supernatant was removed. The wash was repeated once more. In a separate Eppendorf tube a 60 uL solution was made with MES buffer and the DNA aptamer with final concentrations of $25 \mathrm{mM}$ and $2 \mathrm{mg} / \mathrm{mL}$, respectively. The solution was added to the beads and incubated on the rotator for 30 minutes. A $30 \mathrm{uL}$ solution of $100 \mathrm{mg} / \mathrm{mL}$ EDC was made immediately before use in cold $100 \mathrm{mM}$ MES buffer. The solution was mixed with the beads and then $10 \mathrm{uL}$ of $25 \mathrm{mM}$ MES buffer was added for a final volume of $100 \mathrm{uL}$. The beads were incubated at $4^{\circ} \mathrm{C}$ overnight on the rotator. After the incubation, the beads were washed with $50 \mathrm{mM}$ Tris buffer for 15 minutes at room temperature. The magnet was applied for two minutes and the supernatant was removed. The wash was repeated three more times. The beads were resuspended in binding buffer and stored at $4^{\circ} \mathrm{C}$ until use. Control beads were made following the same procedure without the addition of the DNA aptamer. The $60 \mathrm{uL}$ solution was made with MES buffer and Milli-Q® water. 


\subsubsection{CYN Capture}

The beads were washed with binding buffer for 15 minutes three times. A $100 \mathrm{uL}$ sample of $75 \mu \mathrm{M} C Y N$ was added to the beads and was incubated for $2 \mathrm{~h}$ on the rotator at room temperature. The magnet was applied for two minutes. The supernatant was removed and placed in a 2 mL HPLC vial for analysis. Milli-Q® water was then added to the beads at a volume of $200 \mu \mathrm{L}$. The beads were mixed for $12 \mathrm{~h}$ on the rotator at room temperature. The magnet was applied for two minutes and the supernatant was placed in a $2 \mathrm{~mL}$ HPLC vial for analysis. The beads were washed three times as previously mentioned and the procedure was repeated with the $100 \mu \mathrm{M}$ and $150 \mu \mathrm{M}$ CYN samples.

\subsubsection{HPLC of AAC Samples}

Each concentration of CYN produced three samples for HPLC after incubation with the beads. The sample collected after the addition of CYN, the sample collected after the elution with Milli-Q® water and the wash sample were analyzed to determine the percent recovery of CYN. The analysis was performed on a Shimadzu HPLC. A Kinetex 2,6u C18 100A, 100 x 4.6 mm column was used for analysis. The injection volume of the sample was $20 \mu \mathrm{L}$ and the sample was monitored at $262 \mathrm{~nm}$. The mobile phase consisted of HPLC water (A) and acetonitrile (B). The flow rate was 0.27 $\mathrm{mL} / \mathrm{minute}$. The gradient method is listed in Table 5 . 
Table 5. Time program for detection of CYN

\begin{tabular}{|l|l|l|}
\hline Time (min) & \% Solvent A & \% Solvent B \\
\hline $0-15$ & $98-90$ & $2-10$ \\
\hline $15-18$ & $90-98$ & $10-2$ \\
\hline $18-20$ & 98 & 2 \\
\hline
\end{tabular}

\subsection{Urea PAGE Gel}

\subsubsection{Gel Preparation}

The gel was prepared by mixing $10.5 \mathrm{~g}$ of urea, $5 \mathrm{~mL}$ of $5 \mathrm{X}$ TBE buffer $(445 \mathrm{mM}$ Tris base, 445mM Boric acid, 10mM EDTA) and $9.4 \mathrm{~mL} \mathrm{40 \%} \mathrm{(w/v)} \mathrm{acrylamide.} \mathrm{The}$ solution was stirred using a magnetic stir bar until the urea dissolved. Once the urea dissolved, $139 \mu \mathrm{L}$ of $10 \%$ (w/v) APS and $13.2 \mu \mathrm{L}$ of TEMED was added to the solution. The solution was then quickly poured between the gel plates and the well comb was placed. The gel was left to polymerize for $30 \mathrm{~min}$.

\subsubsection{Gel Samples}

The samples analyzed with the Tecan plate reader were used for the gel. The samples were made with $5 \mu \mathrm{L}$ of the fluorescence sample and $10 \mu \mathrm{L}$ of the gel loading dye. The DNA ladder did not contain a length up to 62 bases, which is the length of the DNA aptamer so $1 \mu \mathrm{L}$ of $1 \mu \mathrm{M}$ DNA aptamer was added to the ladder sample. 


\subsubsection{Running and Imaging the Gel}

The gel was set up in the gel apparatus and was pre-run for an hour to remove any molecules in the gel. The gel was loaded with $3 \mu \mathrm{L}$ of each sample. Once the samples were loaded, the gel was run for 3.5 hours. The gel was removed from the gel plates and was placed in a container with a stain mixture of TBE buffer and SYBR gold. The gel was agitated in the stain every $5 \mathrm{~min}$ for $25 \mathrm{~min}$. The gel was cleaned with ethanol and imaged using a Bio-Rad ChemiDoc system.

4. Results and Discussion

\subsection{Fluorescent Biosensing}

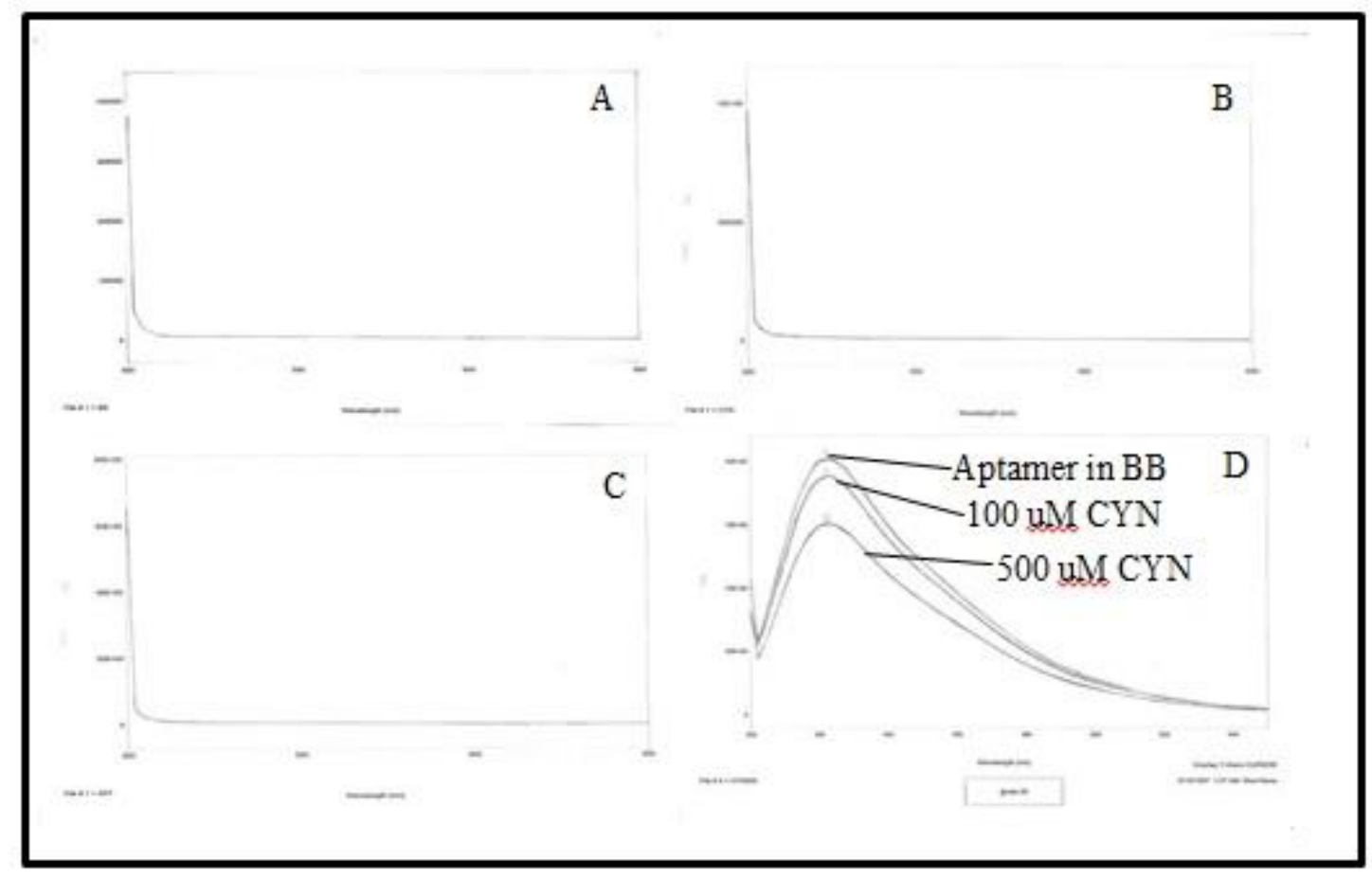

Figure 2. Fluorescent spectrum of (A) Binding buffer (BB), (B) CYN in BB, (C) Aptamer in BB, (D) Aptamer in BB (top) $100 \mathrm{uM} \mathrm{CYN}$ and Aptamer in BB (middle) and $500 \mathrm{uM}$ CYN and Aptamer in BB (bottom) 


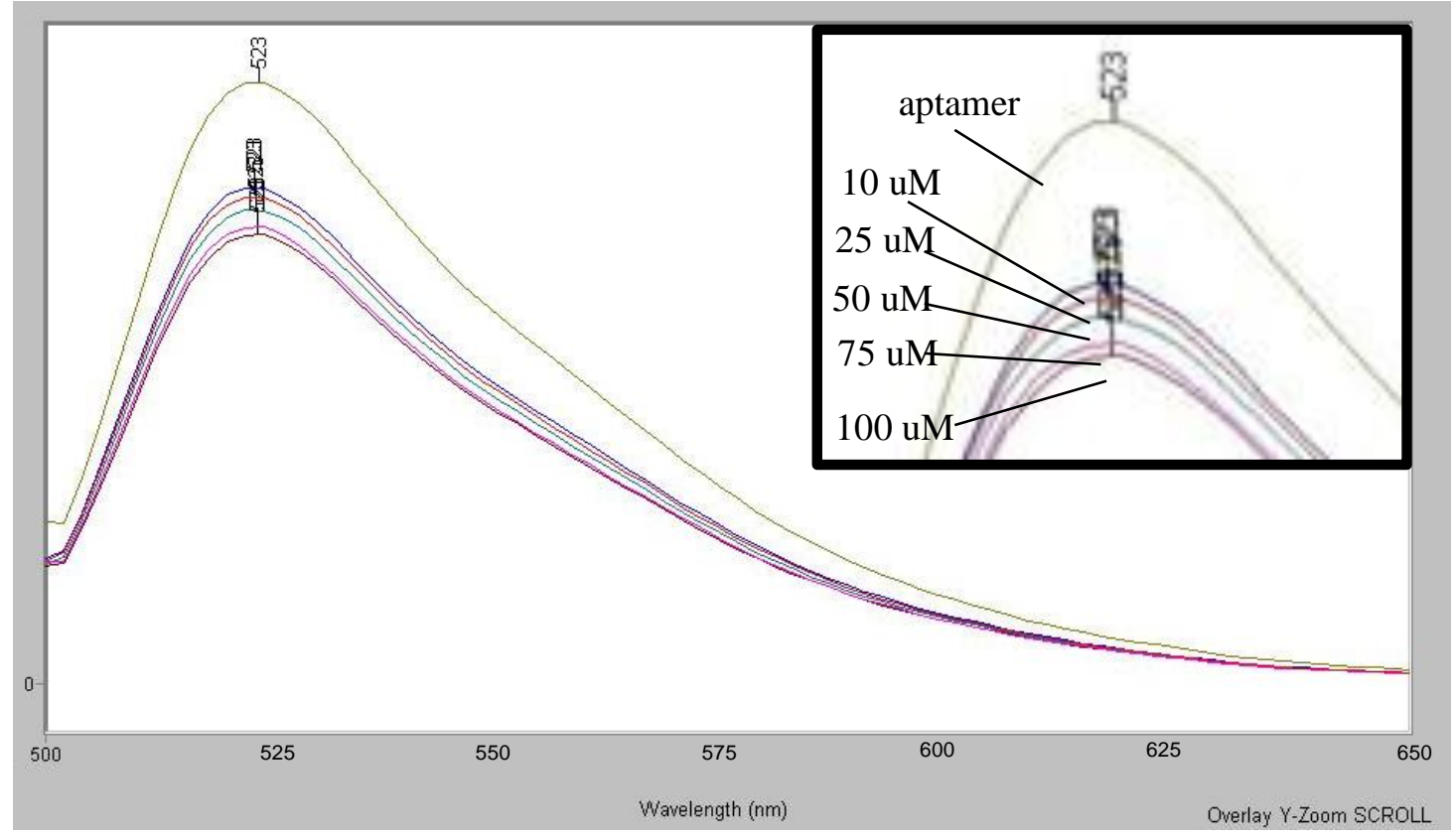

Figure 3. Fluorescence spectrum of Aptamer in BB and after the addition of $10 \mathrm{uM} \mathrm{CYN}$ (10 uM), $25 \mathrm{uM} \mathrm{CYN} \mathrm{(25} \mathrm{uM),} 50 \mathrm{uM} \mathrm{CYN} \mathrm{(50} \mathrm{uM),} 75 \mathrm{uM} \mathrm{CYN} \mathrm{(75} \mathrm{uM),} \mathrm{and} 100 \mathrm{uM}$ CYN (100 uM).

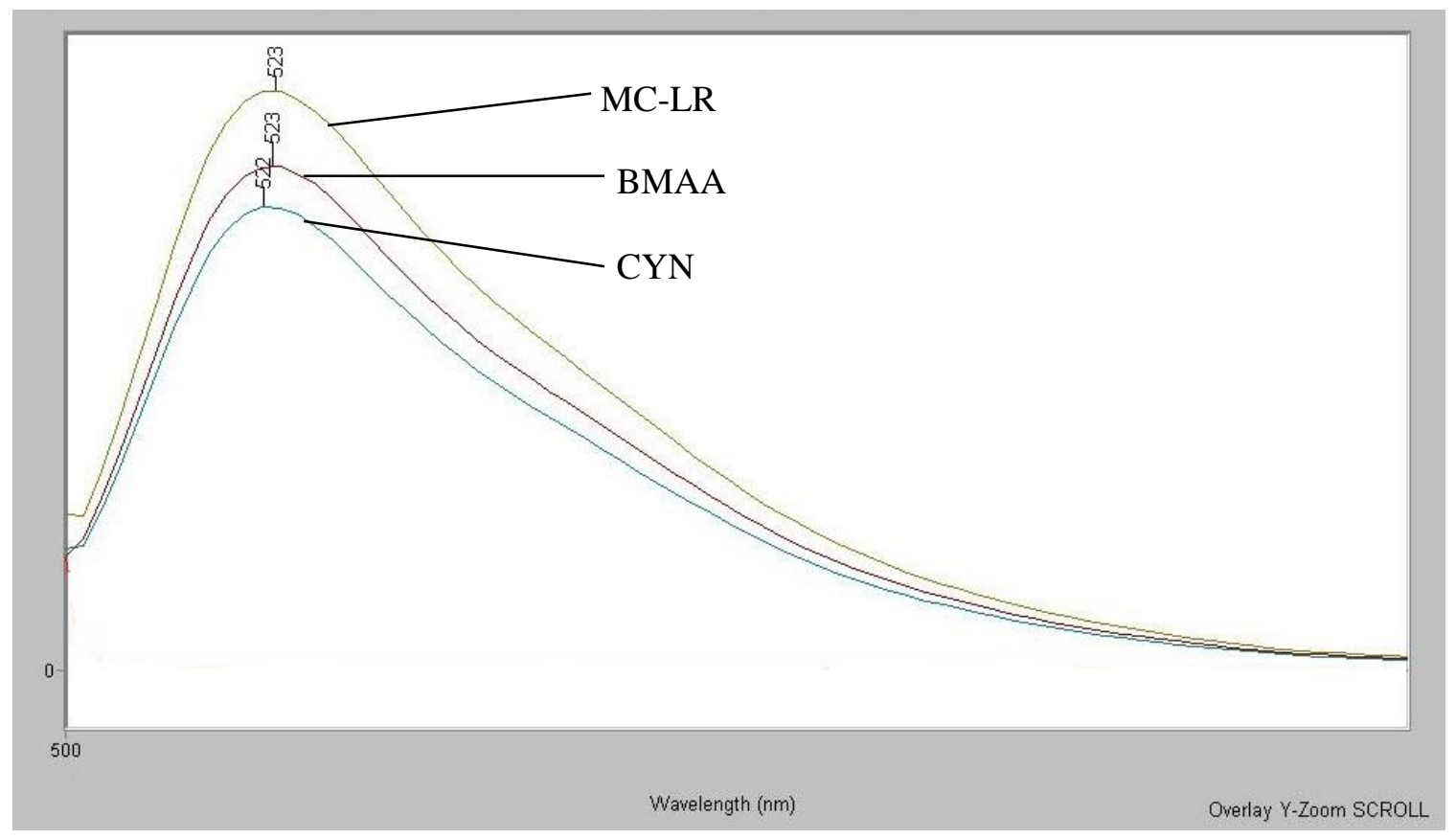

Figure 4. Fluorescent spectrum of aptamer after the addition $100 \mathrm{uM}$ Microcystin-LR (MC-LR), 100 uM BMAA (BMAA), and $100 \mathrm{uM} \mathrm{CYN} \mathrm{(CYN)}$ 


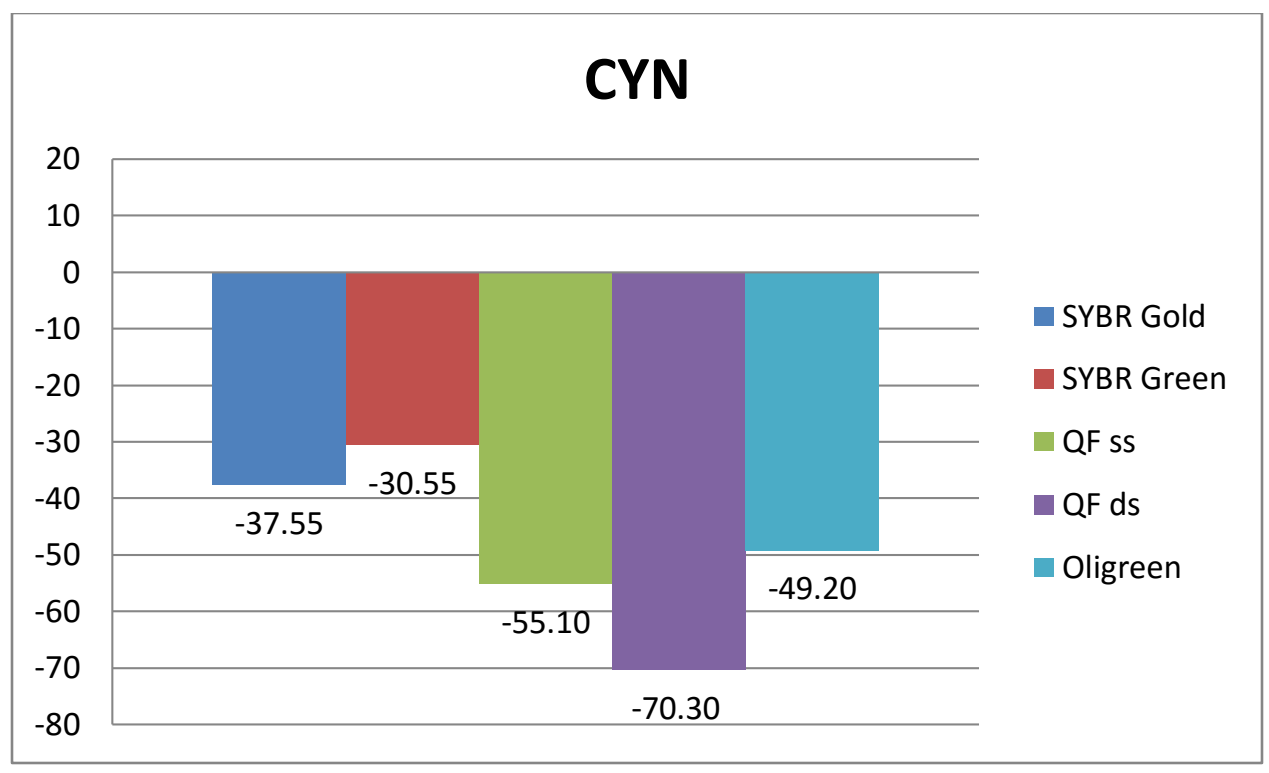

Figure 5. Percent gain of CYN with five different fluorescent probes

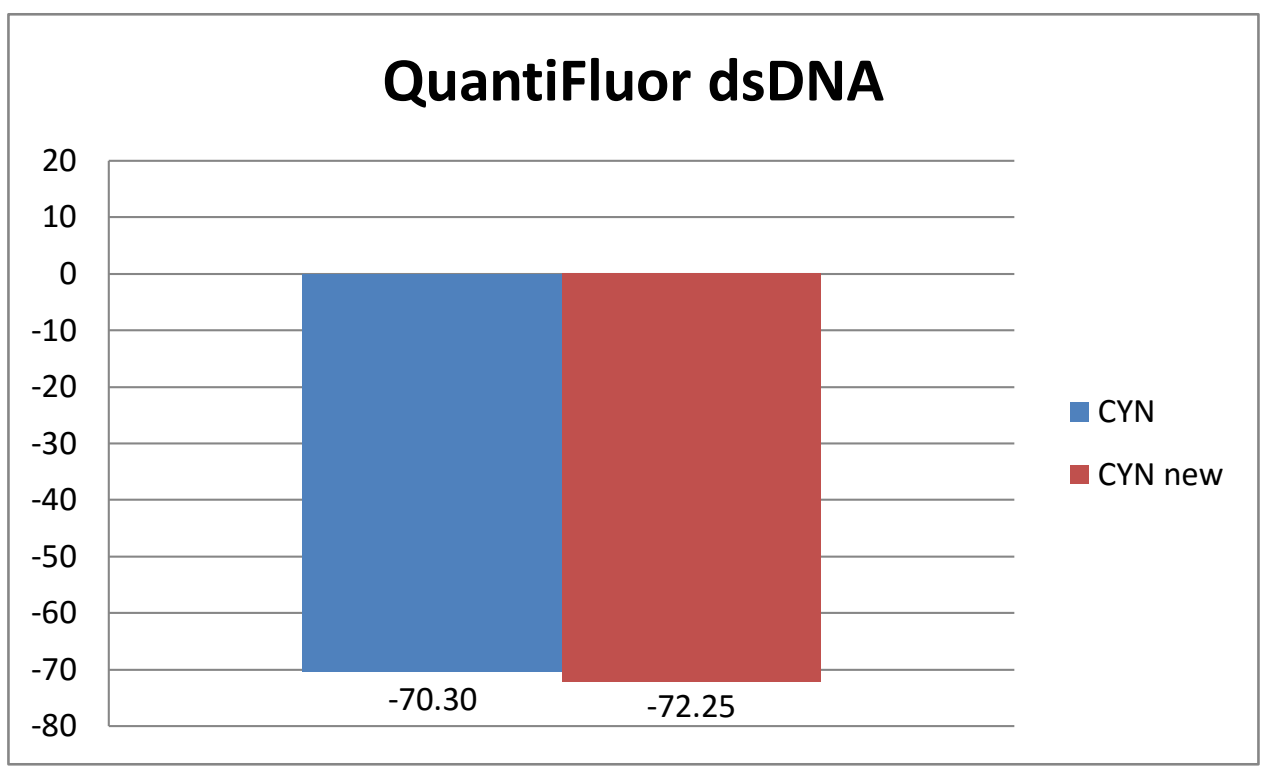

Figure 6. Percent Gain of CYN using QuantiFluor dsDNA probe 


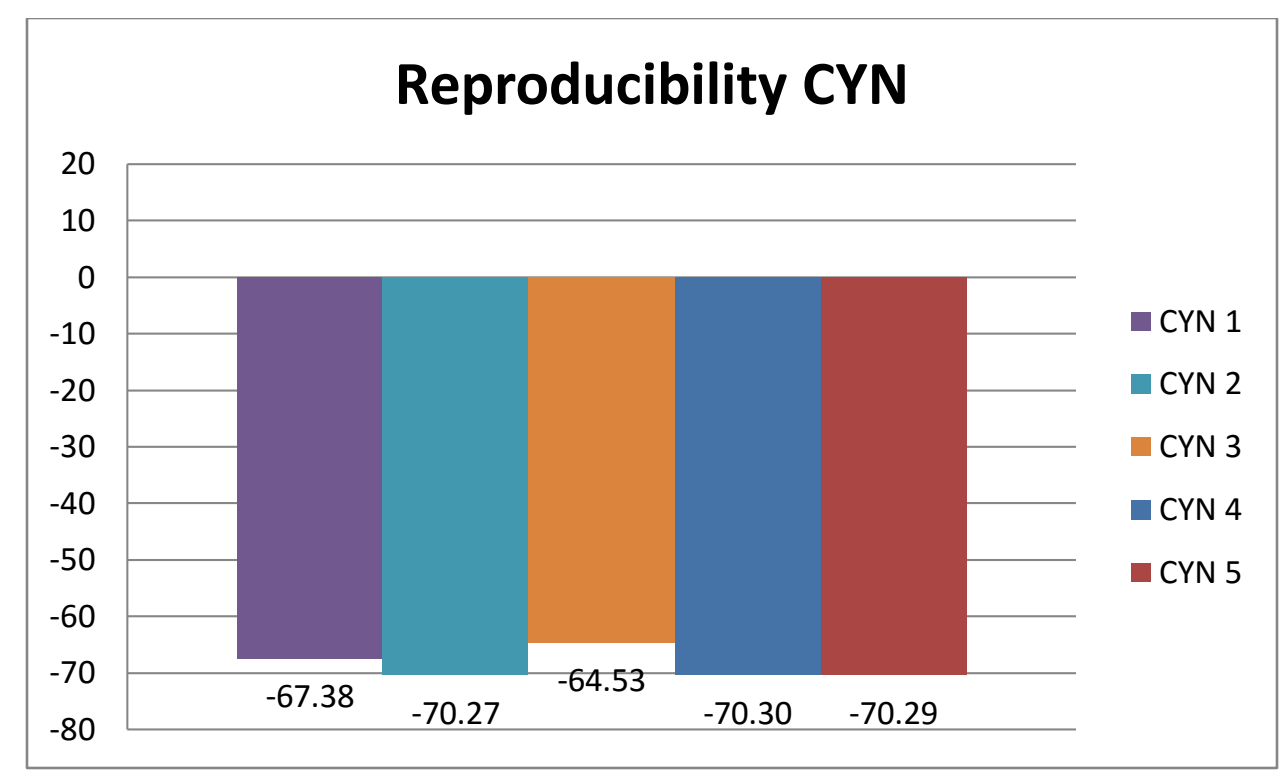

Figure 7. Reproducibility of Percent Gain of CYN using QuantiFluor dsDNA probe

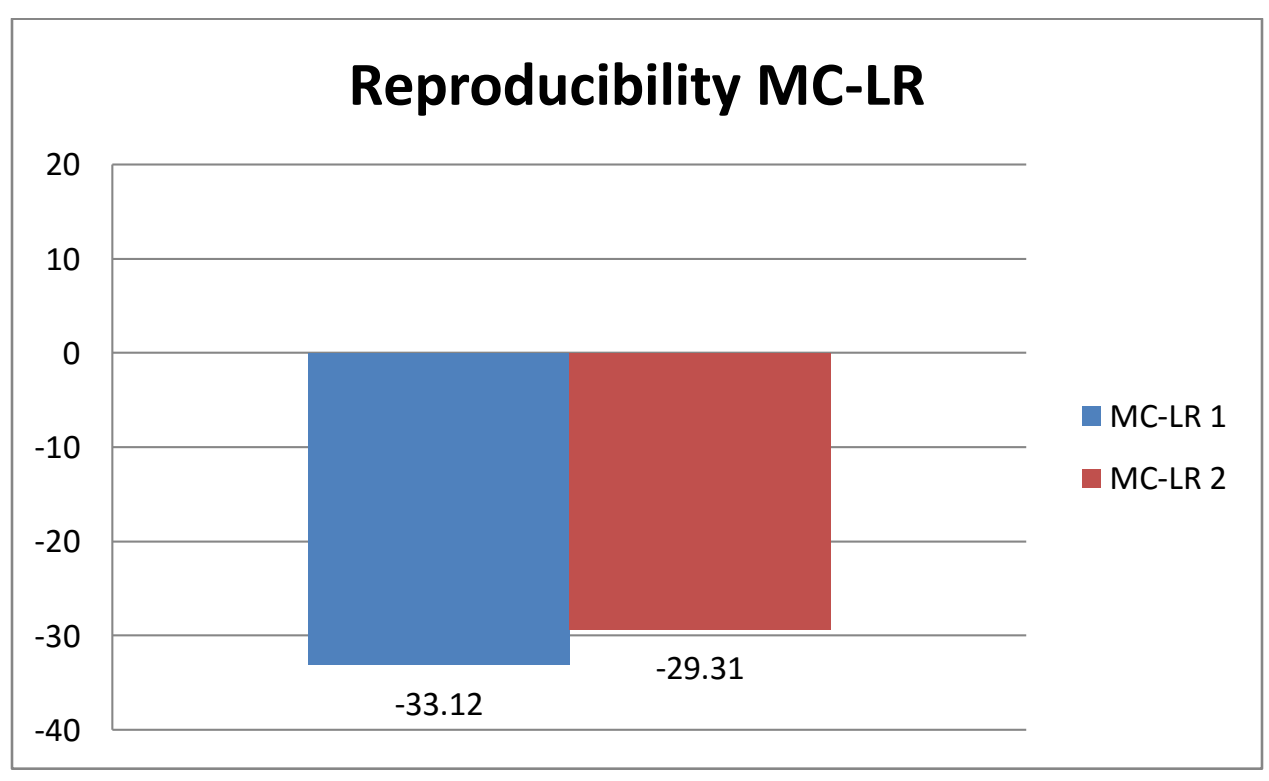

Figure 8. Reproducibility of Percent Gain of MC-LR using QuantiFluor dsDNA probe 


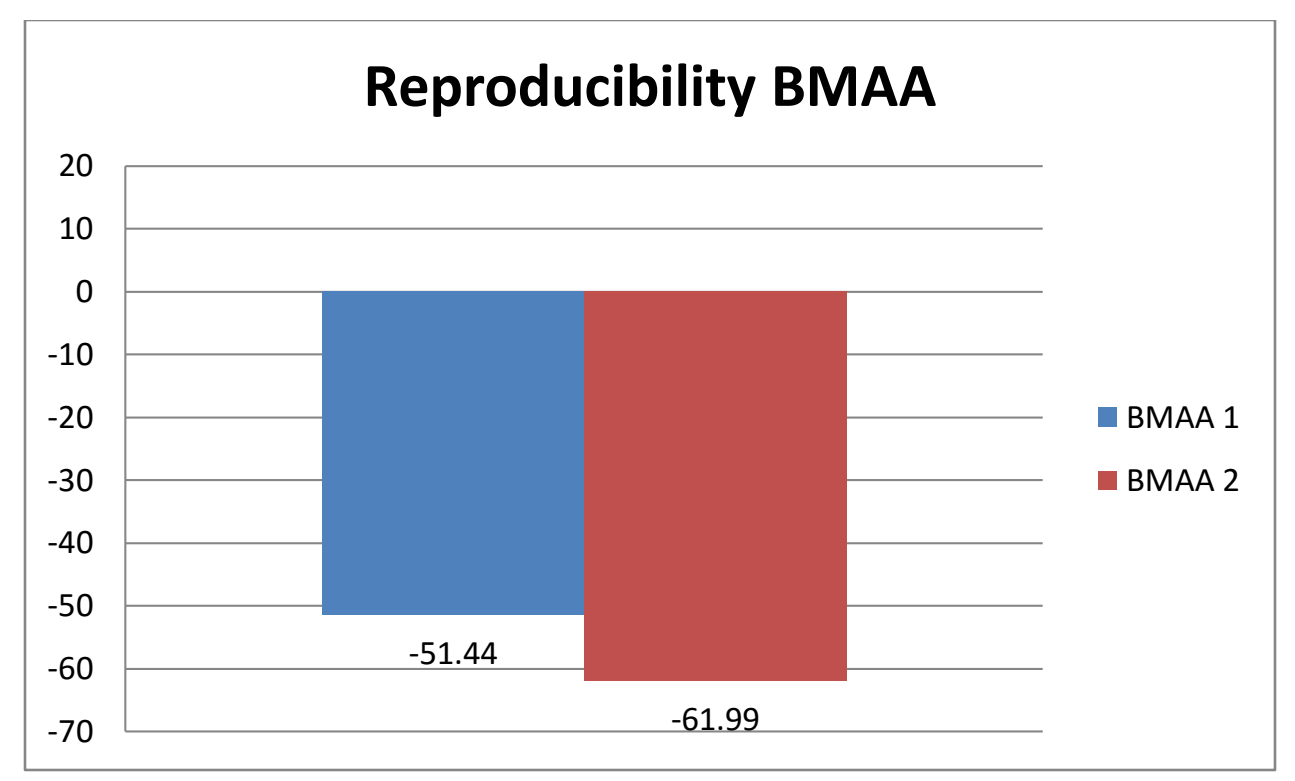

Figure 9. Reproducibility of Percent Gain of BMAA using QuantiFluor dsDNA probe

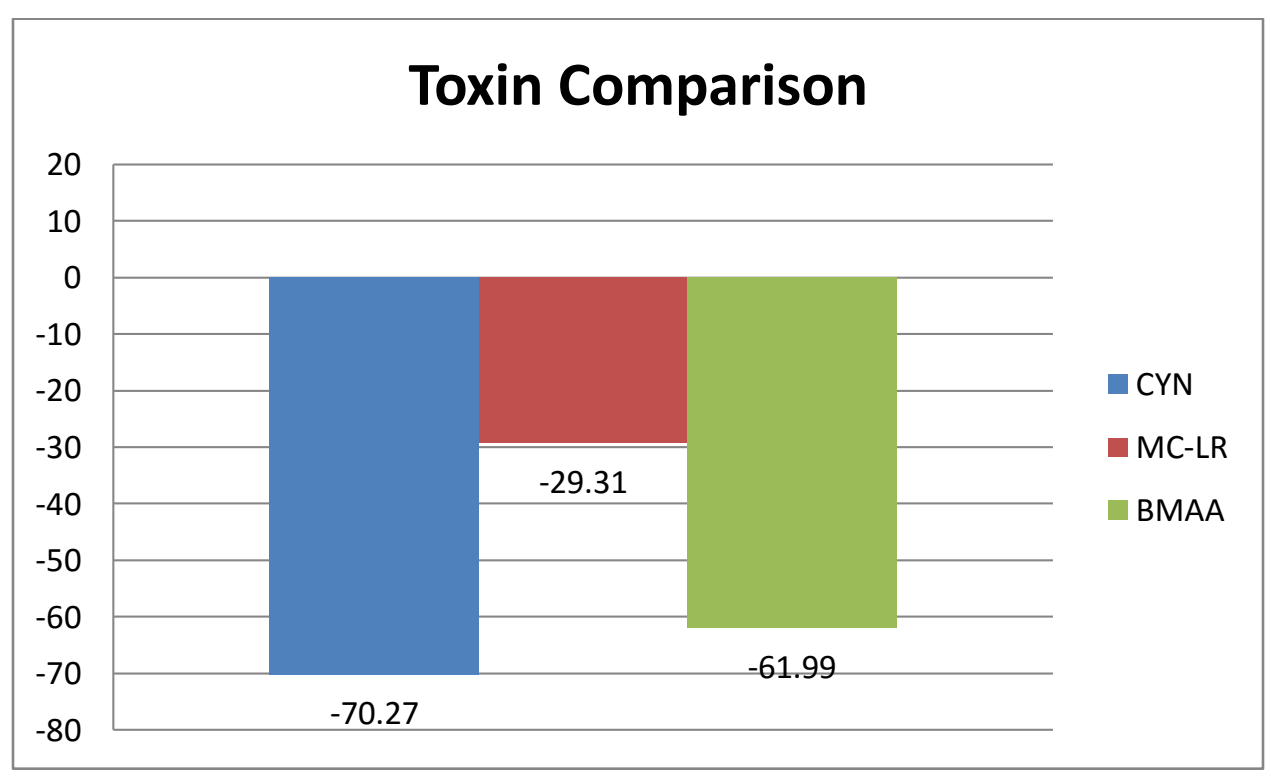

Figure 10. Comparison of Percent Gain of the three toxins with QuantiFluor dsDNA probe

The fluorescence spectrum of the multiple concentrations of CYN (Figure 2D and 3) shows a decrease in signal as the concentration of CYN increases. The decrease in 
signal suggests that the CYN is binding to the aptamer and causing the release of the fluorescent dye from the aptamer. The spectrum of the aptamer with different toxins (Figure 4) shows a decrease in signal. The desired result would have been for a decrease in signal to only occur in the presence of CYN. The results suggest that the specificity of the aptamer is not as high as previously reported in Elshafey et al. [33]. Elshafey et al. tested for change in electrochemical signal with MC-LR and another cyanotoxin, anatoxin. The paper reported no obvious change in signal with MC-LR. The aptamer was exposed to BMAA to test another toxin that has been detected in similar environments as CYN. This toxin exhibited a larger change in signal than MC-LR but a smaller change in signal than CYN. This suggests that BMAA binds to the aptamer stronger than MC-LR but has a weaker affinity than CYN. The five fluorescent probes were tested to determine which probe resulted in the largest change in signal (percent gain) as shown in Figure 5. The QuantiFluor dsDNA provided the largest change in signal when analyzing the control sample in comparison to the sample with CYN added to the aptamer. The QuantiFluor dsDNA was tested to determine if the probe gave consistent results. The QuantiFluor dsDNA data in Figure 6 provided consistent results for percent gain. The data have an average $71.28 \%$ and a standard deviation of 0.98 . The QuantiFluor dsDNA probe was then used for all other fluorescence samples. The five CYN samples in Figure 7 were analyzed after 30 min of incubation to determine if the samples were reproducible. The percent gain of CYN had an average of $68.55 \%$ and a standard deviation of 2.5. The change in signal suggests that $\mathrm{CYN}$ is binding with the aptamer causing the release of the probe at a high rate. There was a $68.55 \%$ change in signal in only $30 \mathrm{~min}$. The samples of MC-LR in Figure 8 were analyzed after a $30 \mathrm{~min}$ 
incubation. The average percent gain was $31.2 \%$ with a standard deviation of 1.9 .

Although the change is relatively small, any change in signal conflicts the original report of Elshafey et al. that reports no obvious change in electrochemical signal with the aptamer incubated with MC-LR. The change in fluorescent signal was observed in both the data from the fluorimeter as well as the Tecan data in Figure 8. The BMAA samples in Figure 9 were analyzed after a 30 min incubation. The average gain was $56.72 \%$ with a standard deviation 5.3. Although the standard deviation of the samples was high, the large signal change suggests binding. The paper by Elshafey et al. did not test BMAA for an electrochemical signal change. The large signal change suggests that the aptamer is not specific for CYN. The comparison of the percent gain of the three toxins in Figure 10 shows that percent gain of the BMAA is similar to that of the CYN. The MC-LR sample percent gain though much lower is still an obvious change.

\subsection{Circular Dichroism}
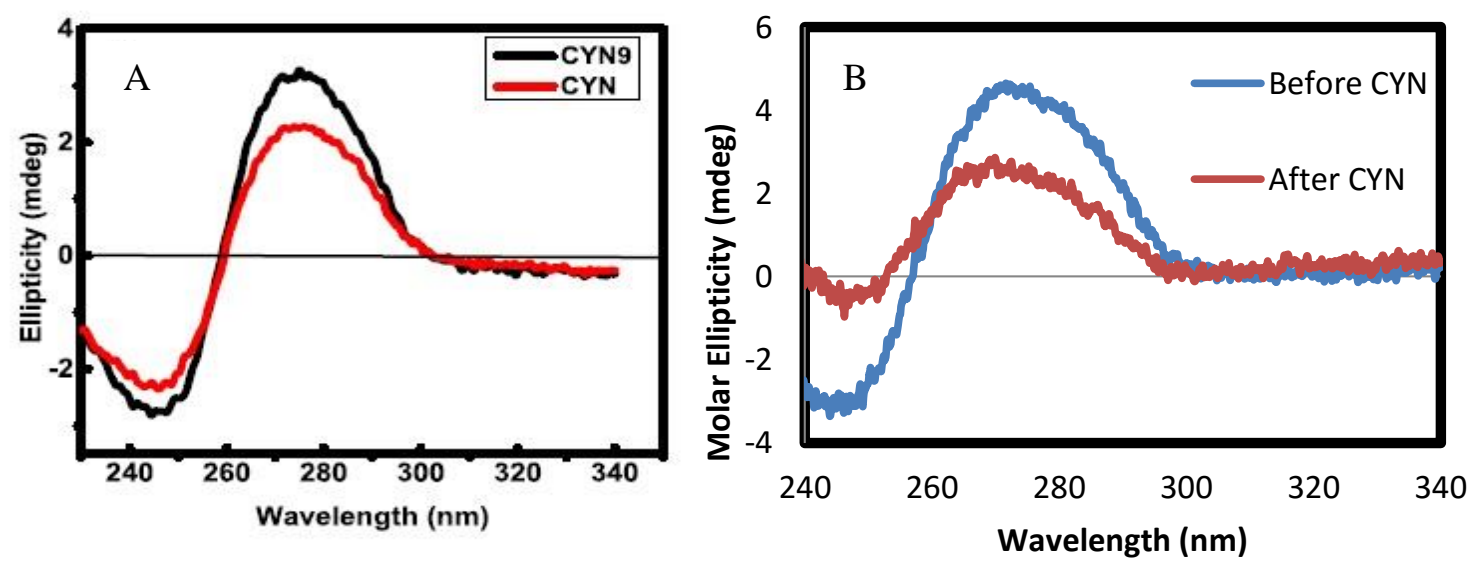

Figure 11. CD spectrum of (A) $1 \mathrm{uM}$ aptamer before and after the addition of $2 \mathrm{uM} \mathrm{CYN}$ performed by Elshafey et al. [33] and (B) $1 \mathrm{uM}$ aptamer before and after the addition of 2 uM CYN 
The CD spectra in Figure 11B is very similar to the one performed by Elshafey et al. (Figure 11A). The two spectra suggest the aptamer forms a B-DNA duplex. The BDNA duplex has a characteristic positive band at $278.5 \mathrm{~nm}$ and a negative band at 248 nm. A decrease in ellipticity when CYN was added suggests that a conformational change occurs.

\subsection{Aptamer Affinity Capture}
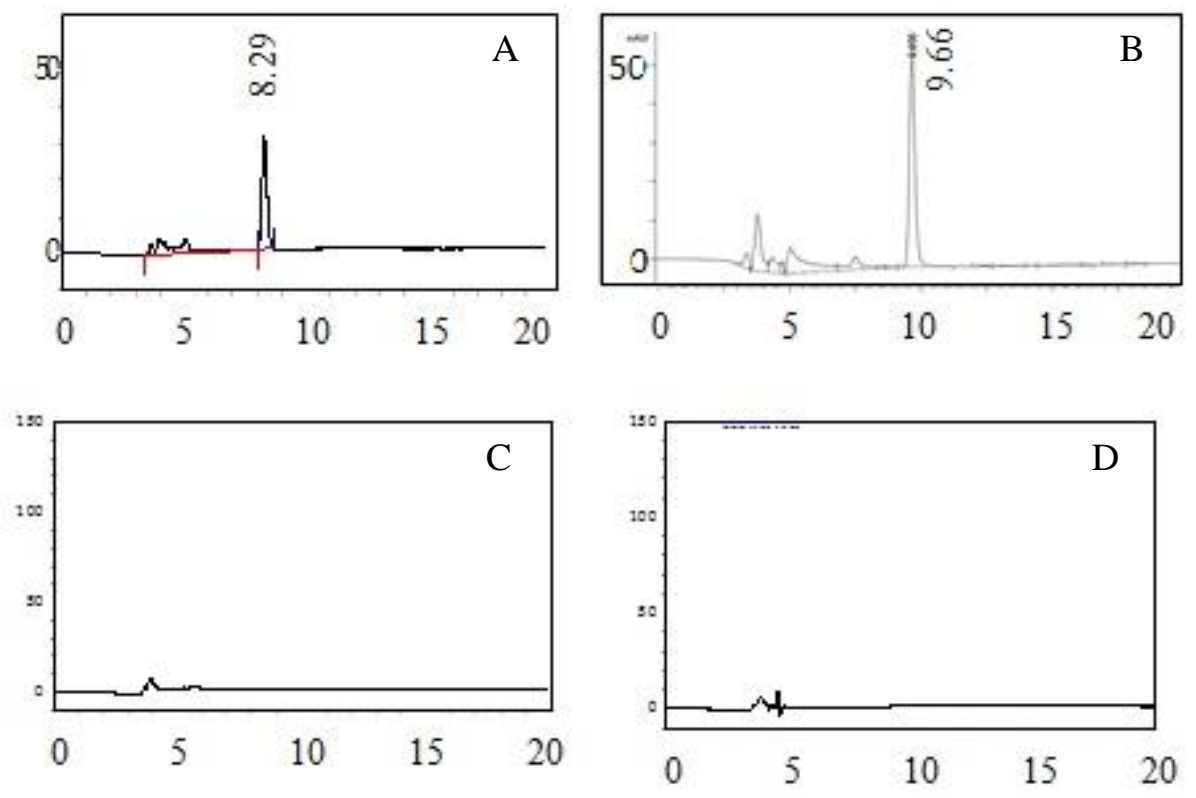

Figure 12. Chromatogram of (A) supernatent after incubation with beads, (B) $75 \mathrm{uM}$ CYN standard, (C) supernatant after elution with Milli-Q® water, (D) supernatant after wash with BB

The peak at 8.29 minutes in Figure 12A displays the presence of CYN in the supernatant after the addition of CYN. The peak suggests that all the CYN in the addition sample did not bind to the aptamer that was bound to the beads. There is no peak in Figure $12 \mathrm{C}$ after the elution step suggesting that the CYN that was bound to the 
aptamer did not elute and is still bound to the aptamer. The CYN could be bound tightly to the aptamer as the binding constant of $88.78 \mathrm{nM}$ reported by Elshafey et al. suggests a high affinity for CYN. The absence of a peak in Figure 12C can also be explained if the amount of CYN that was bound to the aptamer was eluted but the concentration was too long for detection on the HPLC. Cylindrospermopsin has been shown to be genotoxic and cause DNA breakage [44]. The CYN concentration could be at a level that causes minor DNA breakage. The breakage could explain the appearance of a peak in the supernatant sample after the addition of $75 \mathrm{uM} \mathrm{CYN}$. If the CYN was degrading the DNA then some of the CYN would be in the addition sample because the DNA would break at the binding site of CYN. The intact DNA would bind to a percentage of CYN and the rest of the CYN sample would come out in the supernatant. The possibility of the aptamer degrading in the presence of CYN was then investigated. Another explanation for the peak in the supernatant fraction would be that there was an overabundance of CYN in relation to the aptamer or free binding sites on the aptamer. There would be an excess of CYN which would be removed in the supernatant fraction. 


\subsection{Urea PAGE Gel}

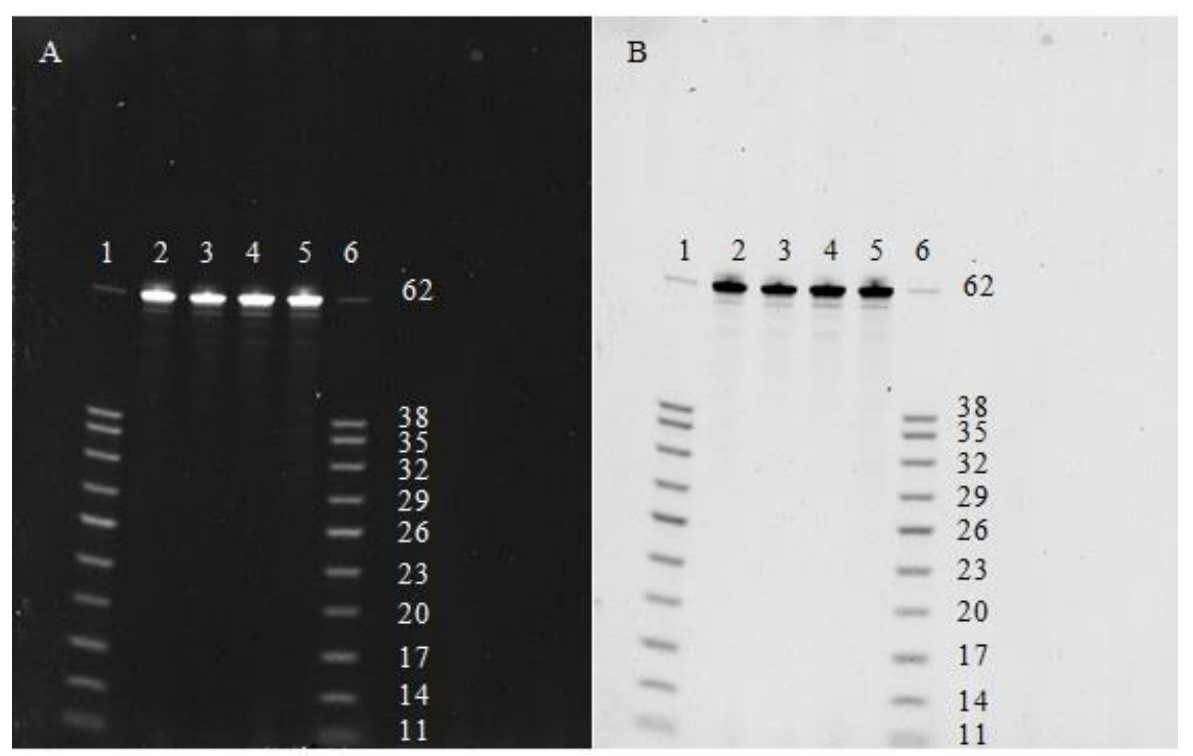

Figure 13. (A) Urea PAGE Gel of DNA ladder (1), Aptamer (2), Aptamer and CYN (3), Aptamer and MC-LR (4), Aptamer and BMAA (5), and DNA Ladder (6), (B) inverse of gel (A)

The gel in Figure 13 shows that there are no additional bands in any of the samples with toxin. Since the samples do not show degradation of DNA which means degradation is not the cause of the AAC not working.

\section{Conclusions}

The health risk that cylindrospermopsin poses to humans and their food chains makes the identification and utilization of an aptamer an important topic to study. Aptamers are an emerging tool and have been proven to be of use for small molecules. The cost effectiveness of aptamers and the specificity that aptamers offer make them a great option for the detection of cyanotoxins. Contamination of water supplies can be determined with minimal cost and greater accuracy. The studies on an aptamer for CYN 
need to be investigated further to optimize binding and determine the applications of AAC for CYN.

The fluorescent binding studies and CD performed in this work showed that CYN does bind to the aptamer as reported in the Elshafey et al. paper. The CD from the paper was reproducible and confirmed a B-DNA complex of the aptamer. The fluorescent binding studies confirmed the author's conclusion that CYN binds to the aptamer. The fluorescence data showed that a change in gain occurred for both the MC-LR and BMAA. The author tested MC-LR and reported no obvious change in the electrochemical signal. The fluorescent data for MC-LR showed a small but significant signal change. The results for BMAA showed a large signal change that was similar to CYN. The authors did not test for BMAA, which is a much smaller toxin. The small size may play a role in its ability to bind to the aptamer since CYN is a smaller molecule as well. The binding of BMAA and the aptamer should be further investigated to determine if the aptamer has a strong affinity for BMAA as well as CYN. The aptamer should also be tested with other toxins to determine if there is a functional group or type of toxins that the aptamer binds to. This would help differentiate which functional groups on the toxins bind to the aptamer.

The HPLC data for the aptamer affinity capture showed that the CYN may have bound to the aptamer on the beads. There are multiple explanations for the absence of a CYN peak in the elution sample. The CYN may not have been eluted and are still bound to the beads. The CYN could have eluted off the beads but at a low concentration the CYN may not have been detected by the HPLC. The urea PAGE gel proved the 
unbound CYN in the addition sample fraction was not an effect of DNA degradation by CYN.

A new aptamer should be investigated as well since the fluorescent data showed that the aptamer identified in Elshafey et al. may not be specific for CYN. The aptamer reported in the Elshafey et al paper is an option for aptamer affinity capture but the use of the aptamer for detection or purification in an aptamer affinity chromatography method needs to be investigated further to determine the proper eluent to remove the CYN from the beads. An aptamer affinity chromatography method for CYN could greatly benefit the areas in which CYN blooms form. The ability to quickly and accurately detect CYN contamination in water supplies could protect a large quantity of people and their food sources. 


\section{LIST OF REFERENCES}

[1] Nicholson, Brenton C.; Humpage, Andrew E.; Papageorgiou, John. Determination and Significance of Emerging Algal Toxins (cyanotoxins). 2007,

[2] Yoo, Richard Scott. Cyanobacterial (blue-green Algal) Toxins: A Resource Guide. American Water Works Association. 1995, 12-71.

[3] Kinnear, Susan. Cylindrospermopsin: A Decade of Progress on Bioaccumulation Research. Marine Drugs. [Online] 2010, 8. doi: 10.3390/md8030542.

<http://www.mdpi.com/1660-3397/8/3/542/htm>

[4] Walsh, Patrick J.; Smith, Sharon; Fleming, Lora; Solo-Gabriele, Helena; Gerwick, William H. Oceans and Human Health: Risks and Remedies from the Seas; Elsevier: Burlington, MA, 2008. pp 281-283.

[5] Humpage, A. R.; Falconer, I. R.; Oral Toxicity of the Cyanobacterial Toxin Cylindrospermopsin in Male Swiss Albino Mice: Determination of No Observed Adverse Effect Level for Deriving a Drinking Water Guideline Value. Environmental Toxicology. [Online] 2003, 18(2). doi:10.1002/tox.10104 <http://onlinelibrary.wiley.com.ezproxy.fiu.edu/doi/10.1002/tox.10104/pdf>

[6] Sarma, T.A. Handbook of Cyanobacteria. 2012, 488-492.

[7] Gupta, S. Cyanobacterial toxins: Microcystin LR. WHO Guidelines for drinking water quality. World Health Organization. 1998, 83-97. <http://www.who.int/water_sanitation_health/dwq/2edaddvol2a.pdf>

[8] Figure from BeagleBioproducts. <http://beaglebioproducts.com/toxinproducts/cylindrospermopsin/\#lightbox/0/>

[9] Griffiths, Dilwyn J.; Saker, Martin L. The Palm Island Mystery Disease 20 Years On: A Review of Research on the Cyanotoxin Cylindrospermopsin. Environmental Toxicology. [Online] 2003. 18(2). doi: 10.1002/tox.10103 <http://onlinelibrary.wiley.com.ezproxy.fiu.edu/doi/10.1002/tox.10103/pdf>

[10] Falconer, Ian R.; Hardy, Stephen J.; Humpage, Andrew R.; Froscio, Suzanne M.; Tozer, Greg J.; Hawkins, Peter R. Hepatic and renal toxicity of the blue-green alga (cyanobacterium) Cylindrospermopsis raciborskii in male Swiss albino mice.

Environmental Toxicology. [Online] 1999, 14(1).

<http://onlinelibrary.wiley.com.ezproxy.fiu.edu/doi/10.1002/(SICI)15227278(199902)14:1\%3C143::AID-TOX18\%3E3.0.CO;2-H/pdf> 
[11] Shen, Xiaoyun; Lam, P.K.S.; Shaw, G.R.; Wickramasinghe, W. Genotoxicity investigation of a cyanobacterial toxin, cylindrospermopsin. Toxicon. [Online] 2002, 40. $<$ http://ac.els-cdn.com/S0041010102001514/1-s2.0-S0041010102001514main.pdf? tid=1bf2a6d6-ce39-11e3-966500000aacb362\&acdnat=1398623222_e222587a80b2c156cb085729081abf9e>

[12] Ohtani, Ikuko; Moore, Richard E.; Maria T. C. Runnegar. Cylindrospermopsin: A Potent Hepatotoxin from the Blue-Green Alga Cylindrospermopsis raciborskii. Journal of the American Chemical Society. 1992, 114. $<$ http://pubs.acs.org.ezproxy.fiu.edu/doi/pdf/10.1021/ja00046a067>

[13] Froscio, Suzanne M.; Humpage, Andrew R.; Burcham,Philip C.; Falconer, Ian R. Cylindrospermopsin-Induced Protein Synthesis Inhibition and Its Dissociation from Acute Toxicity in Mouse Hepatocytes. Environmental Toxicology. [Online] 2003, 18(4). $\langle$ http://onlinelibrary.wiley.com.ezproxy.fiu.edu/doi/10.1002/tox.10121/pdf〉

[14] Berry, John P.; Lind, Owen. First Evidence of "paralytic shellfish toxins" and cylindrospermopsin in a Mexican freshwater system, Lago Catemaco, and apparent bioaccumulation of the toxins in "tegogolo" snails (Pomacea patula catemacensis). Toxicon. [Online] 2009, 55. doi:10.1016/j.toxicon.2009.07.035< <http://ac.elscdn.com/S0041010109003833/1-s2.0-S0041010109003833-main.pdf?_tid=d50d251ec444-11e3-9fe600000aacb35f\&acdnat=1397528746_683614960b0c428e867f02d61c5199a5>

[15] Stirling, David; Quilliam, Michael A. First report of the cyanobacterial toxin cylindrospermopsin in New Zealand. Toxicon. [Online] 2001, 39. <http://ac.elscdn.com/S004101010000266X/1-s2.0-S004101010000266X-main.pdf?_tid=58487260c68b-11e3-b0ac$\underline{\text { 00000aab0f01\&acdnat=1397778933_0bd16533d19198f9cc9c9f8bd59fa3d5> }}$

[16] Welker, Martin; Bickel, Heike, Fastner, Jutta. HPLC-PDA detection of cyllindrospermopsin —opportunities and limits. Water Research. [Online] 2002, 36. $<$ http://ac.els-cdn.com/S004313540200194X/1-s2.0-S004313540200194Xmain.pdf?_tid=c781d5ee-c43e-11e3-a8c0$\underline{\text { 00000aab0f27\&acdnat=1397526151_93c0875aef8b06d4d52868ce8f290e9b }>}$

[17] Eaglesham, Geoffrey K.; Norris, Ross L.; Shaw, Glen R.; Smith, Maree J.; Chiswell, Robyn K.; Davis, Bradley C.; Neville, Gerard R.; Seawright, Alan A.; Moore, Michael R. Use of HPLC-MS/MS to Monitor Cylindrospermopsin, a Blue-Green Algal Toxin, for Public Health Purposes. Environmental Toxicology. [Online] 1999, 14(1). $<$ http://onlinelibrary.wiley.com.ezproxy.fiu.edu/doi/10.1002/(SICI)15227278(199902)14:1\%3C151::AID-TOX19\%3E3.0.CO;2-D/pdf> 
[18] Bláhová,Lucie; Oravec,Michal; Maršáleka, Blahoslav; Šejnohová, Lenka; Šimek, Zdeněk; Bláha, Luděk. The first occurrence of the cyanobacterial alkaloid toxin cylindrospermopsin in the Czech Republic as determined by immunochemical and LC/MS methods. Toxicon. [Online] 2009, 53. doi: 10.1016/j.toxicon.2009.01.014. <http://ac.els-cdn.com/S0041010109000518/1-s2.0-S0041010109000518main.pdf? tid=e618afd4-cda1-11e3-97d1-

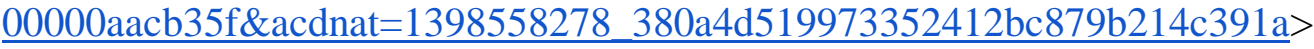

[19] Keefe, Anthony D.; Pai, Supriya; Ellington, Andrew. Aptamers as therapeutics. Nature Reviews Drug Discovery. 2010, 9, 537-550.

[20] Yildirim, Nimet; Long, Feng; Gao, Ce; He, Miao; Shi, Han-Chang; Gu, April Z. Aptamer-Based Optical Biosensor For Rapid and Sensitive Detection of 17 $\beta$-Estradiol In Water Samples. Environmental Science and Technology. [Online] 2012, 46. doi: 10.1021/es203624w <http://pubs.acs.org.ezproxy.fiu.edu/doi/pdf/10.1021/es203624w>

[21] McCauley, Thomas G.; Hamaguchi, Nobuko; Stanton, Martin. Aptamer-based biosensor arrays for detection and quantification of biological macromolecules. Analytical Biochemistry. [Online] 2003, 319. doi: 10.1016/S0003-2697(03)00297-5. <http://ac.els-cdn.com/S0003269703002975/1-s2.0-S0003269703002975main.pdf? tid=d76927e6-ce43-11e3-b11c$\underline{00000 a a c b 361 \& a c d n a t=1398627832 \_814 d 750 b 135 b 47 d 1 a a 092 c 92 d 969 d 5 b a>}$

[22] Queirós, Raquel B.; Noronha, J.P.; Marques, P.V.S.; Sales, M. Goreti F. Emerging (Bio)Sensing Technology for Assessing and Monitoring Freshwater Contamination Methods and Applications. InTech.

$<$ http://docentes.fct.unl.pt/sites/default/files/p214/files/intechemerging_bio_sensing_technology_for_assessing_and_monitoring_freshwater_contamin ation_methods_and_applications.pdf>

[23] Song, Shiping; Wang, Lihua; Li, Jiang; Zhao, Jianlong; Fan, Chunhai. Aptamerbased biosensors. Trends in Analytical Chemistry. [Online] 2008, 27(2). <http://ac.elscdn.com/S0165993607002658/1-s2.0-S0165993607002658-main.pdf?_tid=b3badc12cd90-11e3-8124$\underline{00000 a a b 0 f 01 \& a c d n a t=1398550892 \_a e 34132085386 f 10 \mathrm{ca} 62205 \mathrm{fb} 9483813>}$

[24] Song, Kyung-Mi; Lee, Seonghwan; Ban, Changill. Aptamers and Their Biological Applications. Sensors. [Online] 2012, 12. doi: 10.3390/s120100612. <http://scholar.googleusercontent.com/scholar?q=cache:IjzLgIjqLSIJ:scholar.google.com $\underline{1+\text { Aptamers+and+Their+Biological+Applications\&hl=en\&as_sdt=0,10> }}$ 
[25] Stoltenburg, Regina; Reinemann, Christine; Strehlitz, Beate. SELEX-a (r)evolutionary method to generate high-affinity nucleic acid ligands. Biomedical Engineering. [Online] 2007, 24. doi: 10.1016/j.bioeng.2007.06.001 <http://ac.elscdn.com/S1389034407000664/1-s2.0-S1389034407000664-main.pdf?_tid=cdad0ceec444-11e3-bde400000aacb362\&acdnat=1397528734_85760907f241d8326d5b082d7cdb66c2>

[26] Tang, Jijun; Xie, Jianwei; Shao, Ningsheng; Yan Yan. The DNA aptamers that specifically recognize ricin toxin are selected by two in vitro selection methods. Electrophoresis. [Online] 2006, 27. doi: 10.1002/elps.200500489. $\langle$ http://onlinelibrary.wiley.com.ezproxy.fiu.edu/doi/10.1002/elps.200500489/pdf >

[27] Sampson, Tim. Aptamers and SELEX: the technology. World Patent Information. [Online] 2003, 25. doi: 10.1016/s0172-2190(03)00035-8. <http://ac.els$\underline{\mathrm{cdn} . \mathrm{com} / \mathrm{S} 0172219003000358 / 1-\mathrm{s} 2.0-\mathrm{S} 0172219003000358-\mathrm{main} . \mathrm{pdf} ? \mathrm{tid}=\mathrm{c} 8288244-}$ c444-11e3-ac1d00000aab0f6c\&acdnat=1397528724_44d1a013c1de5efeeb2b2c25ce7da1e4>

[28] Aquino-Jarquin, Guillermo; Toscano-Garibay, Julia D. RNA Aptamer Evolution: Two Decades of SELEction. International Journal of Molecular Sciences. [Online] 2011, 12. doi:10.3390/ijms12129155 <http://www.mdpi.com/1422-0067/12/12/9155/htm>

[29] Djordjevic, Marko. SELEX experiments: New prospects, applications and data analysis in inferring regulatory pathways. Biomedical Engineering. [Online] 2007, 24. doi: 10.1016/j.bioeng.2007.03.001. <http://ac.els-cdn.com/S1389034407000299/1-s2.0S1389034407000299-main.pdf? tid=ca61b314-c444-11e3-bec3$\underline{00000 a a b 0 f 26 \& a c d n a t=1397528732 \_4401 e 1300 f 687 b 626 c a f 571 \mathrm{c} 10 \mathrm{a} 11780>}$

[30] McKeague, Maureen; DeRosa, Maria C.; Challenges and Opportunities for Small Molecules-Aptamer Development. Journal of Nucleic Acids. 2012. pp 1-20 doi:10.1155/2012/748913

[31] Tombelli, S.; Minunni, M.; Mascini, M. Analytical applications of aptamers. Biosensors and Bioelectronics. [Online] 2005, 20. <http://ac.elscdn.com/S0956566304005524/1-s2.0-S0956566304005524-main.pdf?_tid=e493839ece43-11e3-b478$\underline{\text { 00000aacb361\&acdnat=1398627854_85ed8a74e7f7a0315691f3c14bbf9529> }}$ 
[32] Nakamura, Chikashi; Kobayashi, Teruaki; Miyake, Masato; Shirai, Makoto; Miyakea, Jun. Usage of a DNA Aptamer as a Ligand Targeting Microcystin, Molecular Crystals and Liquid Crystals Science and Technology. Section A. Molecular Crystals and Liquid Crystals. [Online] 2001, 371(1). pp 369-374. DOI:10.1080/10587250108024762. <http://www.tandfonline.com.ezproxy.fiu.edu/doi/pdf/10.1080/10587250108024762>

[33] Elshafey, Reda; Siaj, Mohamed; Zourob, Mohammed. In Vitro Selection, Characterization, Biosensing Application of High-Affinity CylindrospermopsinTargeting Aptamers. Analytical Chemistry. 2014 (86). pp 9196-9203.

[34] Fishman, Dmitry. An introduction to circular dichroism spectroscopy. Presentation. University of California Irvine.

[35] Chang, Yu-Ming; Chen, Cammy K.-M.; Hou, Ming-Hon. Conformational Changes in DNA upon Ligand Binding Monitored by Circular Dichroism. International Journal of Molecular Sciences. 2012, 13, 3394-3413. Doi:10.3390/ijms13033394.

[36] McKeague, Maureen; Velu, Ranganathan; Hill, Kayla; Bardóczy, Viola; Mészáros, Tamás; DeRosa, Maria C. Selection and Characterization of a Novel DNA Aptamer for Label-Free Fluorescence Biosensing of Ochratoxin A. Toxins. 2014, 6, 2435-2452. doi: 10.3390/toxins6082435

[37] Romig, Timothy; Bell, Carol; Drolet, Daniel. Aptamer affinity chromatography: combinatorial chemistry applied to protein purification. Journal of Chromatography B. 1999, 731, 275-284.

[38] Zhao, Qiang; Wu, Minghuo; Le, Chris; Li, Xing-Fang. Applications of aptamer affinity chromatography. Trends in Analytical Chemistry. 2012, 41.

[39] Rippka, Rosemarie; Deruelles, Josette; Waterbury, John B.; Hardman, Michael; Stanier, Roger Y. Generic Assignments, Strain Histories and Properties of Pure Cultures of Cyanobacteria. Journal of General Microbiology. 1979, 111, S, 1-61.

[40] Norris, R. L. G.; Eaglesham, G. K.; Shaw, G. R.; Senogles, P.; Chiswell, R. K.; Smith, M. J.; Davis, B. C.; Seawright, A. A.; Moore, M. R.; Extraction and Purification of the Zwitterions Cylindrospermopsin and Deoxycylindrospermopsin from Cylindrospermopsis raciborskii. Environmental Toxicology [Online] 2001, 16(5). $\langle$ http://onlinelibrary.wiley.com.ezproxy.fiu.edu/doi/10.1002/tox.1048/pdf $>$ 
[41] Chiswell, Robyn K.; Shaw, Glen R.; Eaglesham, Geoff; Smith, Maree J.; Norris, Ross L.; Seawright, Alan A.; Moore,Michael R. Stability of Cylindrospermopsin, the Toxin from the Cyanobacterium, Cylindrospermopsis raciborskii: Effect of $\mathrm{pH}$, Temperature, and Sunlight on Decomposition. Environmental Toxicology. [Online] 1999, 14(1). <http://onlinelibrary.wiley.com.ezproxy.fiu.edu/doi/10.1002/(SICI)15227278(199902)14:1\%3C155::AID-TOX20\%3E3.0.CO;2-Z/pdf>

[42] Seifert, Marc; McGregor, Glenn; Eaglesham, Geoff; Wickramasinghe, Wasantha; Shaw, Glen. First evidence for the production of cylindrospermopsin and deoxycylindrospermopsin by the freshwater benthic cyanobacterium, Lyngbya wollei (Farlow ex Gomont) Speziale and Dyck. Harmful Algae. [Online] 2007, 6. doi: 10.1016/j.hal.2006.07.001. <http://www.sciencedirect.com/science/article/pii/S1568988306000801>

[43] Han, Bin; Zhao, Chao; Yin, Junfa; Wang, Hailin. High performance aptamer affinity chromatography for single-step selective extraction and screening of basic protein lysozyme. Journal of Chromatography B. 2012, 903.

[44] D’Anglada, Lesley V.; Strong, Jamie. Drinking Water Health Advisory for the Cyanobacterial Toxin Cylindrospermopsin. Analytical Methods and Treatment Technologies. Environmental Protection Agency. < https://www.epa.gov/sites/production/files/2015-06/documents/cylindrospermopsinreport-2015.pdf>

[45] Chapuis-Hugon, Florence; du Boisbaudry, Aude; Madru, Benjamin; Pichon, Valérie. New extraction sorbent based on aptamers for the determination of ochratoxin A in red wine. Analytical Bioanalytical Chemistry. 2011, 400, 1199-1207. Doi: 10.1007/s00216010-4574-y

[46] Lin, Po-Hsun; Chen, Ren-Hao; Lee, Chung-Han; Chang, Yung; Chen, Chien-Sheng; Chen, Wen-Yih. Studies of the binding mechanism between aptamers and thrombin by circular dichroism, surface plasmon resonance and isothermal titration calorimetry. Colloids and Surfaces B: Biointerfaces. 2011, 88, 552-558.

[47] Kökpinar, Öznur; Walter, Johanna-Gabriela; Shoham, Yuval; Stahl, Frank; Scheper, Thomas. Aptamer-Based Downstream Processing of His-Tagged Proteins Utiizing Magnetic Beads. Biotechnology and Bioengineering. 2011, 1-9. Doi: 10.1002/big.23191

[48] Madru, Benjamin, Chapuis-Hugon, Florence; Pichon, Valérie. Novel extraction supports based on immobilized aptamers: Evaluation for the selective extraction of cocaine. Talanta. 2011, 85, 616-624. Doi: 10.1016/j.talanta.2011.04.016 
[49] Bruno, John G.; Kiel, Johnathan L. Use of Magnetic Beads in Selection and Detection of Biotoxin Aptamers by Electrochemiluminescence and Enzymatic Methods. Drug Discovery and Genomic Technologies. 2002, 32, 178-183.

[50] Moreira, C.; Azevedo, J.; Antunes, A.; Vasconcelos, V. Cylindrospermopsin: occurrence, methods of detection and toxicology. Journal of Applied Microbiology. 2013, $114,605-620$.

[51] de la Cruz, A. A. A review on cylindrospermopsin: the global occurrence, detection, toxicity and degradation of a potent cyanotoxin. Environmental Science: Process and Impacts. 2013, 11, 1979-2003.

[52] Kypr, Jaroslav; Kejnovská, Iva; Renčiuk, Daniel; Vorličková, Michaela. Circular dichroism and conformational polymorphism of DNA. Nucleic Acids Research. 2009, 37, 6,1713-1725.

[53] Garbett, Nichola C.; Ragazzon, Patricia A.; Chaires, Jonathan B. Circular dichroism to determine binding mode and affinity of ligand-DNA interactions. Nature Protocols. 2007, 2, 3166-3172.

[54] Snatzke, Günther. Circular Dichroism: An Introduction. Circular Dichroism: Principles and Applications. 2000, 1-36.

[55] Woody, Robert W. Theory of Circular Dichroism of Proteins. Circular Dichroism and the Conformational Analysis of Biomolecules. 1996, 25-61. 